\title{
Development of Near-Cloud Turbulence Diagnostics Based on a Convective Gravity Wave Drag Parameterization
}

\author{
SoO-Hyun Kim AND Hye-YeOng CHun \\ Department of Atmospheric Sciences, Yonsei University, Seoul, South Korea \\ ROBERT D. SHARMAN AND STANLEy B. TRIER \\ National Center for Atmospheric Research, Boulder, Colorado
}

(Manuscript received 13 November 2018, in final form 31 May 2019)

\begin{abstract}
We propose near-cloud turbulence (NCT) diagnostics for use in aviation turbulence forecasting, using a convective gravity wave drag (CGWD) parameterization scheme. The NCT diagnostics are obtained based on (i) CGWD and (ii) minimum Richardson number including the effects of convective gravity waves (CGWs). The feasibility of the NCT diagnostics is examined using numerical simulation results of real turbulence cases related to the breaking of CGWs, which occurred over eastern Missouri and southwestern Illinois in the United States on 9-10 March 2006, and near Fukuoka, Japan, on 2 September 2007. On 9-10 March 2006, several instances of moderate-or-greater (MOG)-intensity turbulence were reported above shallow but active convection over the central United States, while on 2 September 2007, severe turbulence was encountered above dissipating convection near Fukuoka, Japan. The high-resolution simulation results for both turbulence events show that CGWs and their breaking provide favorable environments for turbulence generation. For two simulated real cases, nonzero NCT diagnostics are reasonably well matched with observed turbulence encounters. The global distribution of CGWD calculated using global reanalysis data revealed a high potential of MOG turbulence in the tropics and the midlatitudes, which can be clearly distinguished from the traditional clear-air turbulence index where high potentials of MOG turbulence are diagnosed in the midlatitudes associated with the strong vertical wind shears near jet streams. These results imply that the proposed NCT diagnostics are useful for forecasting turbulence related to the breaking of CGWs, especially, in tropical regions.
\end{abstract}

\section{Introduction}

Turbulence encounters at cruising altitudes are the major cause of weather-related aviation incidents (Tvaryanas 2003; Sharman et al. 2012; Kim and Chun 2016; Sharman and Lane 2016). According to previous studies (Riddaway 1998; Golding 2000; Williams 2014), the estimated economic loss associated with a compensation for aircraft damage, flight delay, fuel loss, and human injuries exceeds millions of dollars each year. Considering that the global air traffic has increased and will continue to gradually increase (e.g., Warner 2013; Williams 2017), understanding turbulence and properly predicting its occurrence to minimize turbulence-related damage has become an important goal of aviation meteorology.

Among the various sources of turbulence (e.g., jet stream, upper-level fronts, and mountain waves), moist

Corresponding author: Prof. Hye-Yeong Chun, chunhy@yonsei.ac.kr convection is one of the main sources (Hamilton and Proctor 2002; Lane et al. 2012; Kim and Chun 2016; Sharman and Trier 2019). Over the United States, Kaplan et al. (2005) showed that the majority of severe (SEV) turbulence events $(86 \%)$ were laterally less than $100 \mathrm{~km}$ from deep convection and Wolff and Sharman (2008) found that the regions of strong convective activity identified by lightning flash data were well matched with the locations of moderate-orgreater (MOG) turbulence events. Over the northeastern Atlantic and Europe, Meneguz et al. (2016) found that $11 \%$ of MOG turbulence events occur in proximity to the convection. Over South Korea, Kim and Chun (2011) showed that $11 \%$ of MOG turbulence events were associated with convection. Recently, Lee and Chun (2015a) and Kim and Chun (2016) showed that $11 \%$ and $7 \%$ of light-or-greater turbulence events are related to convection over South Korea and East Asia, respectively. 
Turbulence associated with clouds is referred to as convectively induced turbulence (CIT) and can be classified into two categories: in-cloud CIT and out-ofcloud CIT (Pantley and Lester 1990; Lester 1994; Lane et al. 2003; Kim and Chun 2011, 2012a; Kim and Chun 2016; Sharman and Trier 2019). In the current study, the out-of-cloud CIT is referred to as near-cloud turbulence (NCT) following Lane et al. (2012). The occurrence of in-cloud CIT is associated with moist instability within the convective updrafts and turbulent mixing, while NCT can be caused by convective and shearing instability, by convectively induced flow deformation, and breaking of convective gravity waves (CGWs) in the cloudfree air (Lane and Sharman 2008; Kim and Chun 2012a; Sharman and Lane 2016; Sharman and Trier 2019). The CGWs can break into small-scale turbulence and can also perturb environments through momentum changes to the mean flow, which generates turbulence (e.g., Lindzen 1981; Bedard et al. 1986; Lane et al. 2012; Trier et al. 2012).

Unlike in-cloud CIT that pilots can easily recognize and avoid by monitoring radar echoes and satellite images (Monette and Sieglaff 2014), NCT is not easily detected by in-flight radar (Kim and Chun 2012a; Lane et al. 2012), given that the spatial range of turbulent air can extend far from the cloud boundary (Lane et al. 2012; Sharman and Lane 2016; Barber et al. 2018). In this regard, the U.S. Federal Aviation Administration (FAA) established thunderstorm avoidance guidelines (FAA 2012) stating, "Do avoid by at least 20 miles laterally any thunderstorm identified as severe or giving an intense radar echo," and "Do clear the top of a known or suspected severe thunderstorm by at least 1,000 feet altitude for each $10 \mathrm{kt}$ of wind speed at the cloud top." However, Lane et al. (2012) showed that substantial numbers of MOG turbulence reports were observed within a distance of $3.6 \mathrm{~km}$ (vertically) away from the echo top. Monette and Sieglaff (2014) also showed that a higher probability of light-or-greater (LOG) turbulence exists within a distance of $3.6 \mathrm{~km}$ above satellite-inferred cloud-top heights. Currently, the FAA guidelines (FAA 2017) do not include a vertical separation. Although the abovementioned guidelines can help minimize the risk of encountering NCT in ostensibly clear air, many previous NCT studies conducting highresolution numerical simulations (e.g., Lane et al. 2003, 2012; Lane and Sharman 2008; Kim and Chun 2012a; Trier et al. 2012) have demonstrated that these guidelines are insufficient to prevent encounters associated with turbulence surrounding the convection.

The current operational turbulence forecasting methods, Graphical Turbulence Guidance (GTG; Sharman et al. 2006; Sharman and Pearson 2017) and Korean aviation Turbulence Guidance (KTG; Kim and Chun 2012b; Lee and Chun 2015b), have been developed using the numerical weather prediction (NWP) model output and turbulence observations including pilot reports (PIREPs) and automated in situ turbulence observations. These methods mostly include turbulence diagnostics based on the jet stream and upper-level frontogenesis processes. Recently, Pearson and Sharman (2017) investigated a convection-related turbulence forecasting technique that combines the GTG product with CIT diagnostics, including turbulence kinetic energy (TKE), convective available potential energy, and convective inhibition, and the three-dimensional mosaic from the Next Generation Weather Radar (NEXRAD) turbulence detection algorithm (Williams 2014; Sharman and Lane 2016).

A number of previous NCT studies have demonstrated that vertically and horizontally propagating CGWs both directly and indirectly influence the turbulence generation (Lane et al. 2003, 2012; Kim and Chun 2012a; Sharman et al. 2012; Trier et al. 2012; ZovkoRajak and Lane 2014). An example of a direct influence on turbulence is breaking of CGWs or encountering a critical level where the wave horizontal phase speed equals the background flow. An example of an indirect influence on turbulence is the lowering of the gradient Richardson number, which is conducive to the turbulence generation. Trier et al. (2012) investigated the generation mechanism of turbulence encounters that occurred in eastern Missouri and southwestern Illinois on 9-10 March 2006 using nested multiscale simulations. The NCT above active shallow convection occurred because of upward-propagating CGWs and their breaking. In East Asia, Kim and Chun (2012a) investigated the generation mechanism of turbulence encounters above deep convection, which occurred over Fukuoka, Japan, on 2 September 2007, using nested multiscale numerical simulations. The NCT occurred at a cruising altitude of $35000 \mathrm{ft}(10668 \mathrm{~m})$ and was marked by a change in vertical acceleration of $2.26 \mathrm{~g}$ (where $g$ is the gravitational acceleration) over $3 \mathrm{~min}$. Kim and Chun (2012a) identified the process following an updraft collapse as a possible cause of the observed SEV-intensity turbulence event over Japan and noted a potential hazard posed by the dissipated convection. As the convection moved toward the turbulence region with a prevailing southwesterly flow, the convection dissipated. While dissipating, this convection disturbed the prevailing flow and led to enhanced vertical wind shear, resulting in the production of positive $y$ vorticity. This ultimately led to vertical mixing and overturning, which generated turbulence at the cloud boundary. Kim and Chun (2012a) also found that CGWs broke near the turbulence region, which implies their connection with the turbulence generation. Although CGWs can directly 
generate NCT and indirectly provide a favorable environment for the NCT generation, aviation turbulence diagnostics related to CGWs are not included in the current operational forecasting systems of turbulence. Forecasting NCT is challenging because it depends on the cloud characteristics, the near-cloud environmental condition, perturbations to that environment by a cloud circulation and gravity waves (GWs), and the breaking of CGWs (e.g., Sharman and Lane 2016). Because of these complexities, NCT diagnostics suitable for regions containing deep convection have yet to be developed.

In the current study, we develop NCT diagnostics based on the parameterization scheme of convectively induced gravity wave drag (CGWD) proposed by Chun and Baik (1998). The CGWD parameterization by Chun and Baik (1998) has been implemented in both global weather prediction and climate models (Chun et al. 2001, 2004; Saha et al. 2014; Baek 2017; see also http:// www.emc.ncep.noaa.gov/GFS/doc.php). The feasibility of the proposed NCT diagnostics will be examined for MOG-intensity turbulence events on 9-10 March 2006, discussed by Knox et al. (2008) and Trier et al. (2012), and a SEV-intensity turbulence event on 2 September 2007, discussed by Kim and Chun (2012a), using multiscale numerical simulations.

This paper is organized as follows: In section 2, a brief description of turbulence events and an experimental design are provided. In section 3 , the descriptions of the CGWD parameterization and NCT diagnostics proposed in the current study are given. Development of our diagnostics will be based on multiscale simulations using nested domains for the 9-10 March case over the United States (Fig. 1a) and for the 2 September case over East Asia (Fig. 1b). In section 4, simulated MOGintensity NCT events are presented and NCT diagnostics calculated using the model results are compared with the observed turbulence events. In section 5, the global distribution of CGWD, which is one of the proposed NCT diagnostics, is examined using global reanalysis data for a year (from December 2009 to November 2010), and it will be compared with that of the Ellrod1 index (Ellrod and Knapp 1992), which is a commonly used clear-air turbulence (CAT) diagnostic. In section 6 , a discussion and summary are provided.

\section{Case overviews and experimental design}

a. Case overviews

\section{1) 9-10 MARCH 2006 TURBULENCE CASES}

On 9-10 March 2006, four moderate (MOD)-intensity turbulence events and one SEV-intensity turbulence event were reported from PIREPs over the border region of eastern Missouri and southwestern Illinois. The time, latitude, longitude, flight level, and turbulence intensity of the events are presented in Table 1. At 0000 UTC 10 March 2006, widespread precipitation occurred within parts of a large-scale midlatitude cyclone with a distinct prefrontal squall line situated from Indiana to Mississippi (Fig. 2), and relatively shallow convection located below and slightly west of an upper-level southerly jet. Between 2325 UTC 9 March and 0030 UTC 10 March 2006, MOD-intensity and SEVintensity turbulence encounters were reported above the strong and shallow moist convection, which was identified from weather radar reflectivity (Fig. 2c) and infrared (IR) satellite imagery (Fig. 2a). According to Trier et al. (2012), GWs excited from the shallow convection in the jet entrance region propagated vertically when the convection impinged on a lowered tropopause, and some GW overturning occurred several kilometers above the lowered tropopause. In addition to causing turbulence through wave breaking, CGWs indirectly led to turbulence by exciting $\mathrm{KH}$ instability within the layers of strong vertical shear associated with the upper-level convective outflow.

\section{2) 2 SEPTEMBER 2007 TURbULENCE CASE}

At 1034 UTC 2 September 2007, a SEV-intensity turbulence event near Fukuoka $\left(33.68^{\circ} \mathrm{N}, 131.26^{\circ} \mathrm{E}\right)$ at a cruising altitude of $35000 \mathrm{ft}$ was encountered during a flight from Jeju, South Korea, to Osaka, Japan, causing six in-flight injuries. Ahead of the turbulence location, a low pressure system was located between the eastern side of South Korea and Japan and a cold front was situated over the Korea Strait (Fig. 3 of Kim and Chun 2012a). As shown by Kim and Chun (2012a), on the southwestern side of the incident region, isolated convection developed near a prefrontal trough on the warm side of a cold front, and the convection moved northeastward with the prevailing southwesterly flow until 0830 UTC 2 September 2007. After 0830 UTC 2 September 2007, the convection began spreading and weakening and SEV-intensity turbulence was encountered over convection that had significantly dissipated. There was an enhancement of the vertical wind shear of the prevailing southwesterly flow passing through the dissipating convection. The intensified vertical wind shear was associated with a vorticity in $y$ direction and ultimately led to the activation of vertical mixing and overturning, which generated turbulence at the cloud boundary. The breaking of CGWs occurred about $1-2 \mathrm{~km}$ above the dissipating convection where the turbulence incident was reported. The mixing by this process was evidenced by the structure 
(a)

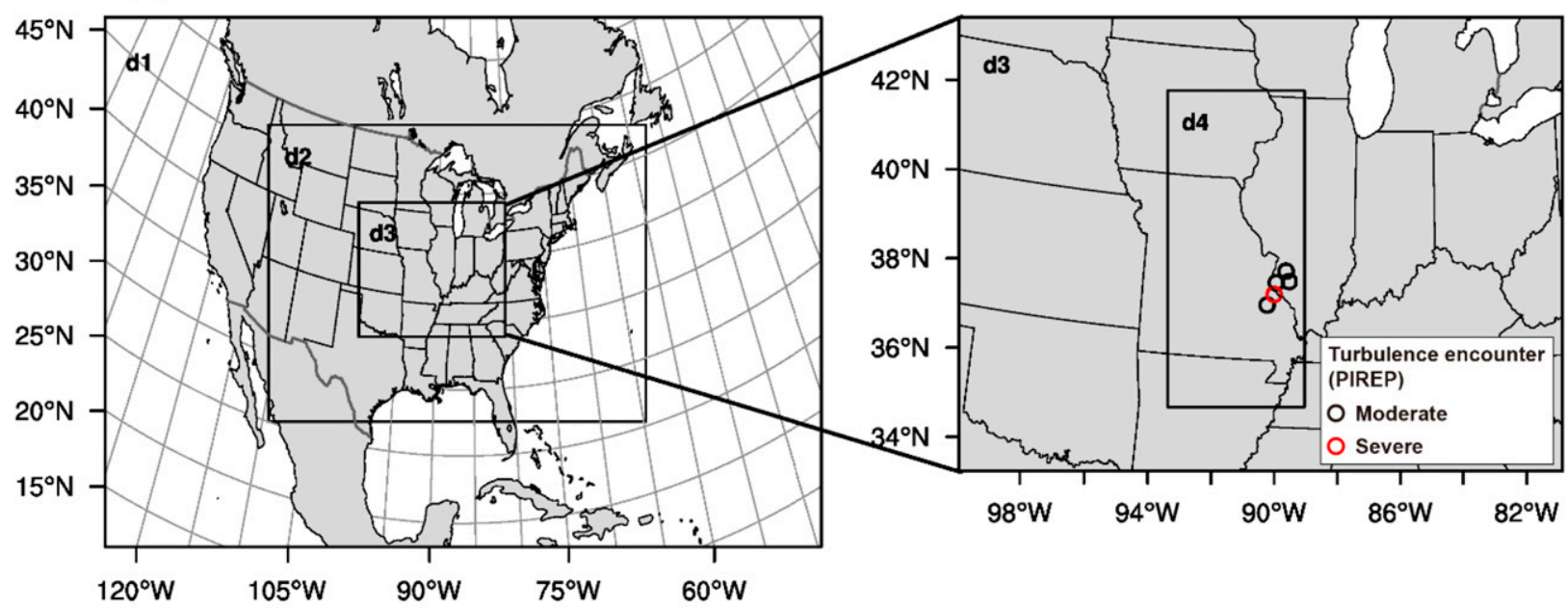

(b)

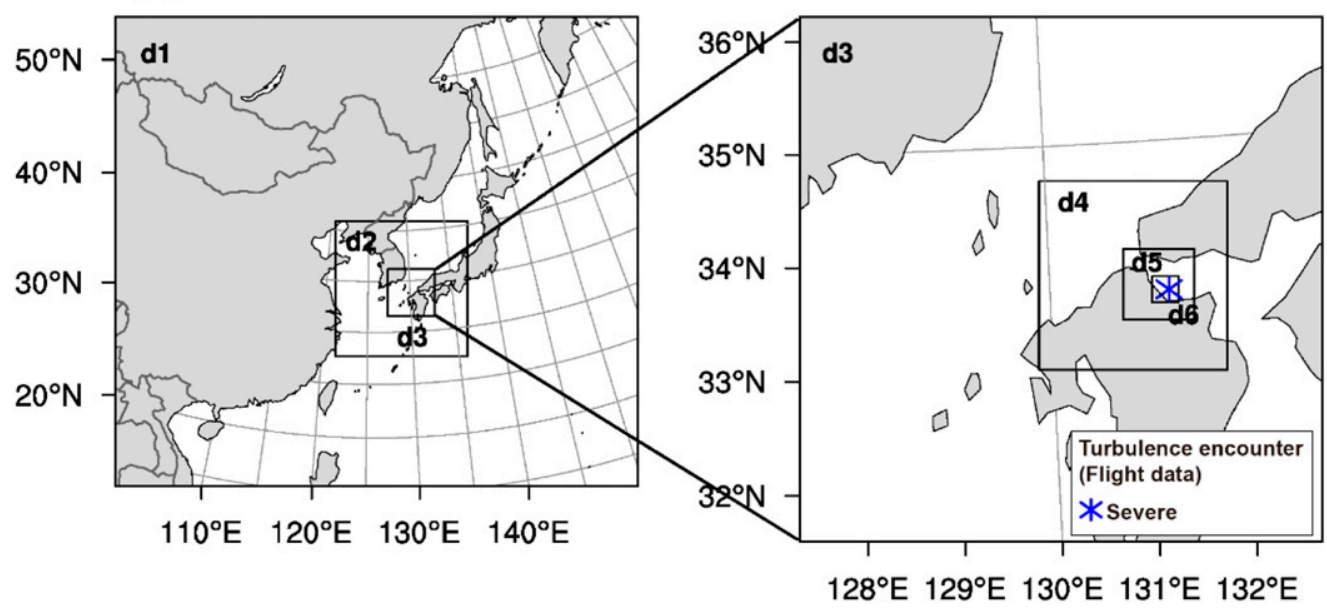

FIG. 1. Model horizontal domains of the (a) 9-10 Mar 2006 (D1, D2, D3, and D4 with 30, 10, 3.3, and 0.67-km horizontal grid spacing, respectively) and (b) 2 Sep 2007 experiments (D1, D2, D3, D4, D5, and D6 with 30, 10, 3.3, 1.1, 0.37, and 0.123-km horizontal grid spacing, respectively) used for the numerical simulations.

of the potential temperature field near the region of the turbulence incident. Breaking of CGWs and resulting turbulence and mixing were also found relatively far from the cloud (about $2-3 \mathrm{~km}$ vertically above the cloud) at $20 \mathrm{~min}$ before the incident time [not shown in this paper, but see Fig. 14 of Kim and Chun (2012a)].

\section{b. Experimental design}

The Advanced Research version of the Weather Research and Forecasting (WRF) Model (ARW-WRF), version 3.8.1 (Skamarock and Klemp 2008), is used in each of our numerical simulations. The ARW-WRF is based on nonhydrostatic and fully compressible prognostic equations with mass-based terrain-following vertical sigma

TABLE 1. Time, longitude, latitude, flight level, and turbulence intensity of five turbulence events included in PIREPs between 2325 UTC 9 Mar and 0030 UTC 10 Mar 2006.

\begin{tabular}{cccccc}
\hline \hline No. & Time $(\mathrm{UTC})$ & Longitude $\left({ }^{\circ} \mathrm{W}\right)$ & Latitude $\left({ }^{\circ} \mathrm{N}\right)$ & Flight level $(\mathrm{ft})$ & Turbulence intensity \\
\hline 1 & 2327 & 89.719 & 38.318 & 39000 & Moderate \\
2 & 2339 & 90.205 & 38.010 & 36500 & Severe \\
3 & 0010 & 90.152 & 38.279 & 37000 & Moderate \\
4 & 0011 & 90.429 & 37.761 & 36000 & Moderate \\
5 & 0024 & 89.833 & 38.550 & 37000 & Moderate \\
\hline
\end{tabular}


(a)

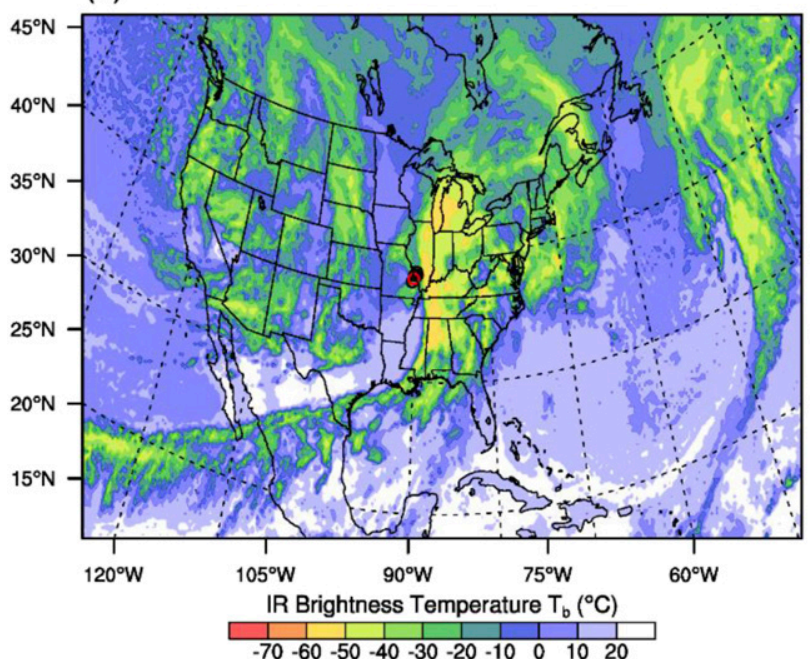

(c)

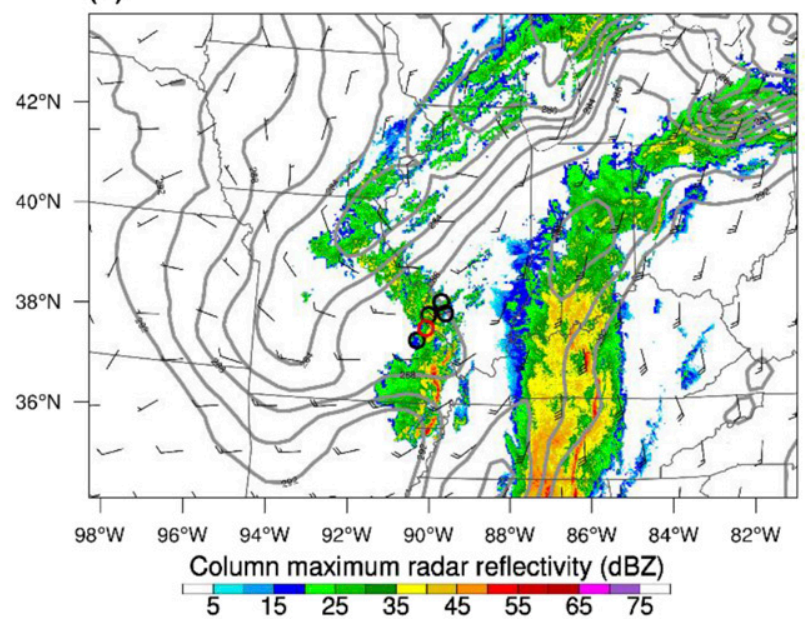

(b)

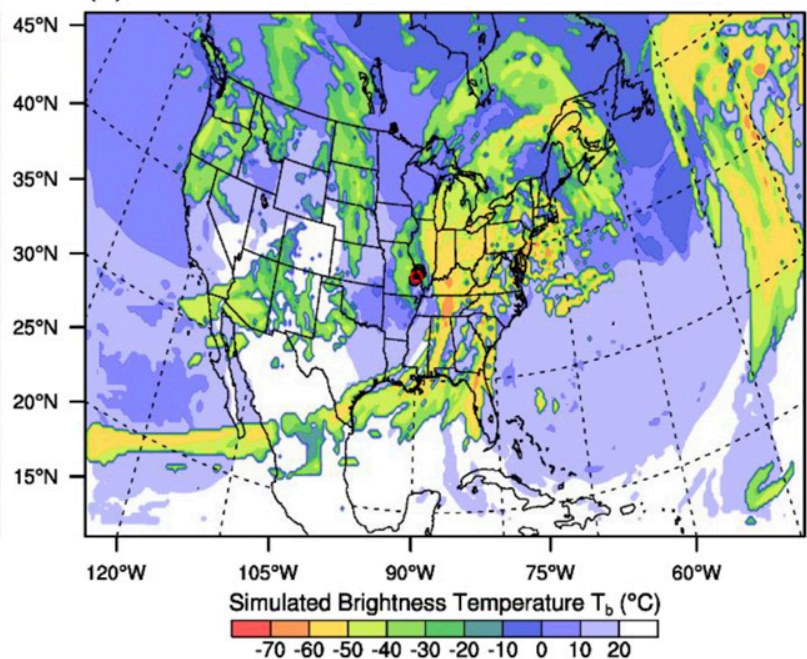

(d)

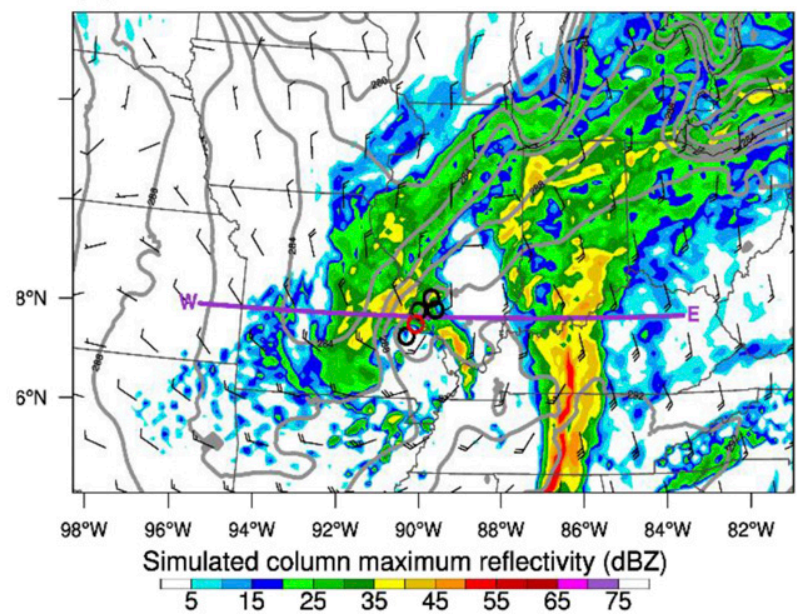

FIG. 2. (a) Observed infrared brightness temperature and (b) simulated brightness temperature in D1 at 0000 UTC 10 Mar. (c) WSR88D NEXRAD radar reflectivity with surface potential temperature (gray contours with 2-K intervals) and surface wind from the RUC model and (d) simulated column-maximum reflectivity with surface potential temperature (gray contours with 2-K intervals) and surface wind in part of D2 at 0000 UTC 10 Mar. Horizontal locations of moderate (black circle) and severe (red circle) turbulence reports are indicated.

levels and a third-order Runge-Kutta time integration scheme. The grid structure of the model is Arakawa C grid staggering. Many previous studies of turbulence encounters have used the ARW-WRF model to reproduce both the synoptic environments and relevant smaller-scale features within which turbulence is generated (e.g., Trier and Sharman 2009, 2016; Kim and Chun 2012a; Trier et al. 2010, 2012; Kim et al. 2014; Lee and Chun 2018).

\section{1) SETUP FOR 9-10 MARCH 2006 CASE}

The experimental design for the 9-10 March 2006 turbulence events is the same as that used in Trier et al. (2012), although an updated version (3.8.1) of the WRF
Model is used in the present study. Figure 1a shows the four fixed two-way interactive nested domains, D1, D2, D3, and D4 with a horizontal spacing of 30,10, 3.33, and $0.67 \mathrm{~km}$, respectively. For all domains, the model top is $20 \mathrm{hPa}$ (about $z=26.5 \mathrm{~km}$ ) with 82 vertical layers. The vertical grid spacing increases linearly from 60 to $240 \mathrm{~m}$ from the surface to the top of the planetary boundary layer (PBL) (about $z=2 \mathrm{~km}$ ) and is approximately $240 \mathrm{~m}$ from 2 to $14 \mathrm{~km}$ above ground level (AGL). From $14 \mathrm{~km}$ AGL to the model top, the vertical grid spacing linearly increases from 240 to $1200 \mathrm{~m}$. To prevent an artificial reflection of gravity waves from the rigid upper boundary, a 7-km absorbing layer is applied, beginning at about $z=19.5 \mathrm{~km}$. As used in Trier et al. (2012), the 
initial condition for most domains, except for D4, and the boundary condition for D1 are obtained from the 6-hourly National Centers for Environmental Prediction (NCEP) global final reanalysis data with a horizontal grid spacing of $1^{\circ}$ longitude by $1^{\circ}$ latitude. The initial conditions for D4 are obtained from the model output of D3 as its parent domain. The model is integrated for $25 \mathrm{~h}$ from 0000 UTC 9 March to 0100 UTC 10 March 2006 for three coarse domains (D1, D2, and D3) and $2 \mathrm{~h}$ from 2300 UTC 9 March to 0100 UTC 10 March 2006 for D4.

The physical parameterizations used in the present simulation include the Lin et al. (1983) bulk microphysical scheme, the Rapid Radiative Transfer Model longwave radiation scheme (Mlawer et al. 1997), the Goddard shortwave radiation scheme (Chou and Suarez 1994), a five-layer thermal diffusion land surface scheme (Dudhia 1996), and the Mellor-YamadaJanjić (MYJ) PBL scheme (Janjić 2001). The horizontal mixing is modeled using a Smagorinsky first-order closure scheme (Skamarock and Klemp 2008), and the Kain (2004) cumulus scheme is exclusively applied to D1 and D2.

\section{2) SETUP FOr 2 SePtember 2007 CASE}

The experimental design for the 2 September 2007 turbulence event is also the same as that used in Kim and Chun (2012a), although, as for the 9-10 March 2006 simulation, an updated version (3.8.1) of the WRF model is used. Figure $1 \mathrm{~b}$ shows the six fixed two-way interactive nested domains, D1, D2, D3, D4, D5, and D6, with a horizontal spacing of $30,10,3.33,1.11,0.37$, and $0.123 \mathrm{~km}$, respectively. Note that the horizontal domain of D1 is the same as the operational regional weather forecasting model of the Korea Meteorological Administration, namely, the Regional Data Assimilation and Prediction System (RDAPS) (http://web.kma.go.kr/ eng/biz/forecast_02.jsp). For all domains, the model top is $20 \mathrm{hPa}$ (about $z=26.5 \mathrm{~km}$ ) with 113 vertical layers. The vertical grid spacing is approximately $50 \mathrm{~m}$ from the surface to the top of PBL (about $z=2 \mathrm{~km}$ ), decreases linearly from 300 to $100 \mathrm{~m}$, from 2 to $9 \mathrm{~km} \mathrm{AGL}$, and is approximately $100 \mathrm{~m}$ from 9 to $13 \mathrm{~km}$ AGL. From $13 \mathrm{~km}$ AGL to the model top, the vertical grid spacing linearly increases from 100 to $500 \mathrm{~m}$. In all domains, a $5-\mathrm{km}$ absorbing layer is applied beginning at about $z=21.5 \mathrm{~km}$, to prevent an artificial reflection of gravity waves from the rigid boundary. As used in Kim and Chun (2012a), the initial conditions for all domains and boundary condition for D1 are obtained from the 6-hourly NCEP global final reanalysis data with the horizontal grid spacing of $1^{\circ}$ longitude by $1^{\circ}$ latitude. The model is integrated for $18 \mathrm{~h}$ from 0000 to 1800 UTC 2 September
2007 for two coarse domains (D1 and D2) and for $9 \mathrm{~h}$ from 0600 to 1500 UTC 2 September 2007 for four fine domains (D3, D4, D5, and D6).

The physical parameterizations used in the present simulation include the Hong and Lim (2006) microphysical scheme, the Rapid Radiative Transfer Model longwave radiation scheme (Mlawer et al. 1997), the Dudhia (1989) shortwave radiation scheme, the Noah land surface model (Chen and Dudhia 2001), and the MYJ PBL scheme (Janjić 2001). The horizontal mixing is modeled using the Smagorinsky first-order closure scheme (Skamarock and Klemp 2008), and the Kain (2004) cumulus scheme is used exclusively in D1 and D2.

Before examining the NCT events, it is worthwhile to note two things. First, while PIREPs are invaluable resources of turbulence research and have been widely used in case studies and statistical analyses for turbulence encounters (e.g., Wolff and Sharman 2008; Lane et al. 2009; Kim and Chun 2011, 2012a; Trier et al. 2012; Lee and Chun 2015a; Trier and Sharman 2016), PIREPs can contain potential time and location errors (Schwartz 1996; Sharman et al. 2014). Sharman et al. (2014) compared the spatiotemporal information from PIREPs with that from the Boeing B737 and B757 automated in situ eddy dissipation rate (EDR) reports and showed that the averaged differences between PIREPs and the in situ EDR data in the horizontal location, vertical location, and time were about $47.8(44.8) \mathrm{km}, 4(33) \mathrm{ft}$, and 10 (159) s for B737 (B757) aircraft, respectively. Second, the location and timing of the convective clouds and turbulence induced by breaking of CGWs from the simulations may not be exactly matched with the observations because of various limitations in the numerical simulations, such as horizontal and vertical resolutions, physical parameterizations, and uncertainties in the initial and boundary conditions. These uncertainties must be considered when comparing observations, especially PIREPs, to model simulation results. Nevertheless, the cluster of turbulence PIREPs on 9-10 March 2006 comprised several different flights, which provides confidence that the turbulence region has been accurately identified.

\section{NCT diagnostics}

In the present study, we propose NCT diagnostics based on the CGWD parameterization by Chun and Baik (1998), which represents turbulence induced by breaking of CGWs above convective clouds.

\section{a. CGWD parameterization}

Chun and Baik (1998) obtained an analytical expression of the gravity wave momentum flux at cloud top based on the two-dimensional, steady-state, linear 
response of a stably stratified flow to a specified thermal forcing representing the latent heating by moist convection in uniform background wind and buoyancy frequency. The CGWD parameterization scheme is activated only at the model grid points where a convective cloud exists, and is computed only above the cloud top. The theoretical details of this CGWD parameterization can be found in Chun and Baik (1998), and here we briefly describe the CGWD parameterization.

First, the wave stress at the cloud top (denoted by subscript ct) is calculated as

$$
\tau_{\mathrm{ct}}=-\left[\rho_{\mathrm{ct}}\left|U_{\mathrm{ct}}\right|^{2} /\left(N_{c t} \Delta x\right)\right] U_{\mathrm{ct}} c_{1} c_{2}^{2} \mu_{\mathrm{ct}}^{2} .
$$

Here, $\rho$ is the air density, $U$ is the basic-state wind, $N$ is the Brunt-Väisälä frequency, and $\Delta x$ is the horizontal grid spacing. The parameter $c_{1}$ is a constant related to the horizontal structure of the prescribed diabatic forcing, which is given by $c_{1}=\pi \ln \left[\left(a_{1}+a_{2}\right)^{2} / 4 a_{1} a_{2}\right]$, where $a_{1}$ represents the half-width of the diabatic forcing and $a_{2}$ is the scale of the widespread cooling that is required for the net heating to be zero in the inviscid, nonrotating, and steady-state flow (Smith and Lin 1982). The halfwidth of the heating $a_{1}$ is approximated by $a_{1} \approx \alpha \Delta x / 2$, where $\alpha$ is the fractional coverage of the subgrid-scale clouds within a grid box and is assumed to be 0.4 as in Chun et al. (2001), and $a_{2}$ is approximated by $a_{2}=5 a_{1}$, following Chun and Baik (1998). The parameter $c_{2}$ is a constant related to the basic-state wind and stability as well as the bottom and top heights of the diabatic forcing, which is defined by $c_{2}=\cos \lambda z_{t}-\cos \lambda z_{b}$, where $z_{t}$ and $z_{b}$ denote the cloud-top and cloud-bottom height, respectively, and $\lambda=N / U$. The $\mu$ is a nonlinearity factor of thermally induced internal GWs (Lin and Chun 1991), which is defined as $\mu=g Q_{0} a_{1} /\left(c_{p} T N U^{2}\right)$, where $g$ is the gravitational acceleration, $T$ is the air temperature (in units of $\mathrm{K}$ ), $Q_{0}$ is the convective heating rate, and $c_{p}$ is the specific heat of air at a constant pressure. In this study, the column-maximum heating rate is used to represent $Q_{0}$. Second, the wave stress above the cloudtop parallel to the wave stress vector at the cloud-top level is calculated using the same formulation of (1) except that the values at each level are used:

$$
\tau=-\left[\rho|U|^{2} /(N \Delta x)\right] U c_{1} c_{2}^{2} \mu^{2} .
$$

Here, $U$ is the basic-state wind projected onto the cloudtop wind vector. Third, the level of wave breaking is identified based on the minimum Richardson number $\left(\mathrm{Ri}_{\text {min }}\right)$ including the effects of CGWs:

$$
\mathrm{Ri}_{\text {min }} \approx \mathrm{Ri} \frac{1-\mu\left|c_{2}\right|}{1+\mu \mathrm{Ri}^{1 / 2}\left|c_{2}\right|^{2}}
$$

where $\mathrm{Ri}$ is the local Richardson number $(\mathrm{Ri}=$ $N^{2} / \eta^{2}$, where $\eta$ is the vertical wind shear defined by $d U / d z$ ). If $\mathrm{Ri}_{\min }$ is $\geq 1 / 4$, we assume that there is no wave breaking and the wave stress is the same as below, whereas if $\mathrm{Ri}_{\min }$ is $<1 / 4$, we assume that wave breaking occurs and the saturated wave stress, which means no further growth of wave amplitude based on Lindzen's linear wave saturation theory (Lindzen 1981), is calculated as

$$
\tau_{s}=-\left[\rho U^{3} /(N \Delta x)\right] c_{1} c_{2}^{2} \mu_{s}^{2} .
$$

Here, $\mu_{s}$ is the nonlinearity factor for wave saturation, which is derived when $\mathrm{Ri}_{\text {min }}$ is set to $1 / 4$ based on Lindzen's linear wave saturation theory (Lindzen 1981):

$$
\mu_{s}=\left|c_{2}\right|^{-1}\left(2 \sqrt{2+\mathrm{Ri}^{-1 / 2}}-2-\mathrm{Ri}^{-1 / 2}\right) .
$$

Note that Palmer et al. (1986) also used the same threshold of $\mathrm{Ri}_{\min }$ for the wave saturation criterion. As mentioned above, although the parameter $c_{2}$ can be obtained for given basic-state wind, stability, and cloudtop and cloud-bottom heights within a fixed range from -2 to 2 , this parameter $c_{2}$ might have a assigned value based on a critical value of the nonlinear factor (Chun and Baik 1998). Baik and Chun (1996) investigated the effects of the nonlinearity factor on the response of an atmosphere to the specified heating in the uniform flow through nondimensional numerical model experiments. Over a wide range of nonlinearity factors with a 0.2 increment ranging from 0 to 4 , they found that the critical value of the nonlinearity factor for the overturning of CGWs is about 2.2. The parameter $c_{2}$ can be approximated from (5) as 0.38 for $\mathrm{Ri} \rightarrow \infty$ and $\mu_{s} \sim 2.2$.

This aforementioned procedure is repeated until the model top is reached. Once the vertical profile of $\tau$ is obtained from the cloud top to the model top, we calculate CGWD using the following equation:

$$
\mathrm{CGWD}=-\frac{1}{\rho} \frac{\partial \tau}{\partial z}
$$

The CGWD in (6) and $\mathrm{Ri}_{\min }$ in (3) will be used to derive eight NCT diagnostics.

\section{b. Development of NCT diagnostics}

Using CGWD and $\mathrm{Ri}_{\text {min }}$, we derive three NCT diagnostics separately from each; (i) the diffusion coefficient $(K)$, (ii) subgrid-scale TKE, and (iii) EDR, which, together with CGWD and $\mathrm{Ri}_{\text {min }}$ themselves, constitute eight individual NCT diagnostics. The diffusion coefficient is derived from the absolute 
value of CGWD using the formulation of Andrews et al. (1987), as

$$
K_{\mathrm{CGWD}} \approx\left|\operatorname{CGWD} \frac{c-U}{N^{2}}\right|,
$$

where $c$ is a horizontal phase speed, which is set to as zero in the current study, because it is assumed that CGWs are stationary relative to the convection. From $\mathrm{Ri}_{\text {min }}$, the diffusion coefficient is derived based on the first-order Smagorinsky closure (Lilly 1962; Smagorinsky 1963), as

$$
K_{\mathrm{Rim}}=\left(C_{s} L\right)^{2}|D| \sqrt{1-\frac{\mathrm{Ri}_{\min }}{\operatorname{Pr}}},
$$

where, the Smagorinsky constant $C_{s}$ is set to 0.2 , $L$ is a length scale set as the vertical grid spacing, and $D=\left\{[(\partial u / \partial x)-(\partial v / \partial y)]^{2}+[(\partial v / \partial x)+(\partial u / \partial y)]^{2}\right\}^{1 / 2}$, is the total deformation, where $u$ and $v$ are zonal and meridional wind components, respectively, and $\operatorname{Pr}$ is the Prandtl number (specified as 1). Using the obtained diffusion coefficient, the subgrid-scale TKE (TKE CGWD $_{\text {T }}$ and $\left.\mathrm{TKE}_{\mathrm{Rim}}\right)$ can be obtained based on the turbulence closure assumptions, using an equation from Deardorff (1980), as

$$
\mathrm{TKE}_{[\mathrm{CGWD}, \mathrm{Rim}]} \approx\left(C_{d}^{-1} \frac{K_{[\mathrm{CGWD}, \mathrm{Rim}]}}{L}\right)^{2},
$$

where, the Deardorff coefficient $C_{d}$ is set to 0.1 , as also used in Lane and Sharman (2008).

Finally, the EDR is calculated according to Lilly (1966):

$$
\mathrm{EDR}_{[\mathrm{CGWD}, \mathrm{Rim}]} \approx\left(\frac{C_{\varepsilon} \mathrm{TKE}_{[\mathrm{CGWD}, \mathrm{Rim}]}^{3 / 2}}{L}\right)^{1 / 3} .
$$

Here, the constant $C_{\varepsilon}$ is set to 0.93 , as suggested by Moeng and Wyngaard (1988). Therefore, the eight diagnostics of NCT (CGWD, Ri $_{\text {min }}, K_{\mathrm{CGWD}}, K_{\mathrm{Rim}}, \mathrm{TKE}_{\mathrm{CGWD}}, \mathrm{TKE}_{\mathrm{Rim}}$, $\mathrm{EDR}_{\mathrm{CGWD}}$, and $\mathrm{EDR}_{\mathrm{Rim}}$ ) are derived in the current study.

The length scales in (9) and (10) can be interpreted as the mixing length and the scale of inertial subrange turbulence, respectively. However, in the current study, the vertical grid spacing is assumed to be the smallest possible scale of turbulence, considering the mixing length can be understood as a diameter of an air parcel prior to turbulent mixing. Although this vertical grid spacing is not optimal, the same length scale for (9) and (10) is used as a simplification. As in this study, Fedorovich et al. (2004) also used the same grid scale for calculation of TKE and EDR.

\section{Model results of NCT events and evaluation of the NCT diagnostics}

\section{a. 9-10 March 2006}

Figure 2 shows the simulated brightness temperature $\left(T_{b}\right)$ in D1 (Fig. 2b) and weather radar reflectivity with surface wind and potential temperature in part of D2 (Fig. 2d), which is compared with the observed IR satellite $T_{b}$ (Fig. 2a) and WSR-88D NEXRAD reflectivity with surface analyses (surface wind and potential temperature) from the Rapid Update Cycle (RUC; Benjamin et al. 2004) with a horizontal grid spacing of $13 \mathrm{~km}$ (Fig. 2c) at 0000 UTC 10 March. The observed $T_{b}$ is obtained from the GridSat-B1 dataset, which has a spatial resolution of $0.07^{\circ}$ (Knapp et al. 2011). The simulated $T_{b}$ is calculated assuming unit optical depth with constant zenith angle and cloud absorption coefficient (Dudhia 1989), and the simulated reflectivity is calculated according to Caine et al. (2013). The overall patterns of simulated $T_{b}$ are similar to the observations, although the magnitudes of $T_{b}$ are different. Compared with the observation (Fig. 2c), the surface cold front is shifted slightly eastward and the wind speed is slightly stronger. Nevertheless, the reported turbulence locations coincide with the regions of the shallow convection with a similar intensity. Accordingly, our simulation results are adequate for use in the calculation of the NCT diagnostics.

Figure 3 shows the simulated vertical velocity interpolated to four different altitudes $(z=9.3,10.3,11.3$, and $12.3 \mathrm{~km}$ ) in D4 at 0000 UTC 10 March. We separate the regions of observed NCT events into two regionsthe right rectangular region covers two turbulence events and the left rectangular region covers three turbulence events. The strong vertical motions are clearly revealed in both regions. For the right rectangular region, the strong motions become weaker at higher altitudes $(12.3 \mathrm{~km})$, while for the left rectangular region, the strong motions are distinctly revealed at each of these four altitudes. Simulated reflectivity indicates that there are regions of active convection over eastern Missouri and western Illinois and that all turbulence regions at the four selected altitudes are located in the cloudfree air, when the cloud boundary is defined by the total cloud condensate with a threshold of $0.01 \mathrm{~g} \mathrm{~kg}^{-1}$ (not shown).

Area averaged vertical cross sections of potential temperature and total cloud condensate are constructed for the two rectangular regions shown in Fig. 3 and are shown in Figs. 4 and 5. At the reported times of the two turbulence events in the right rectangular region (2327 UTC 9 March and 0024 UTC 10 March), amplified 

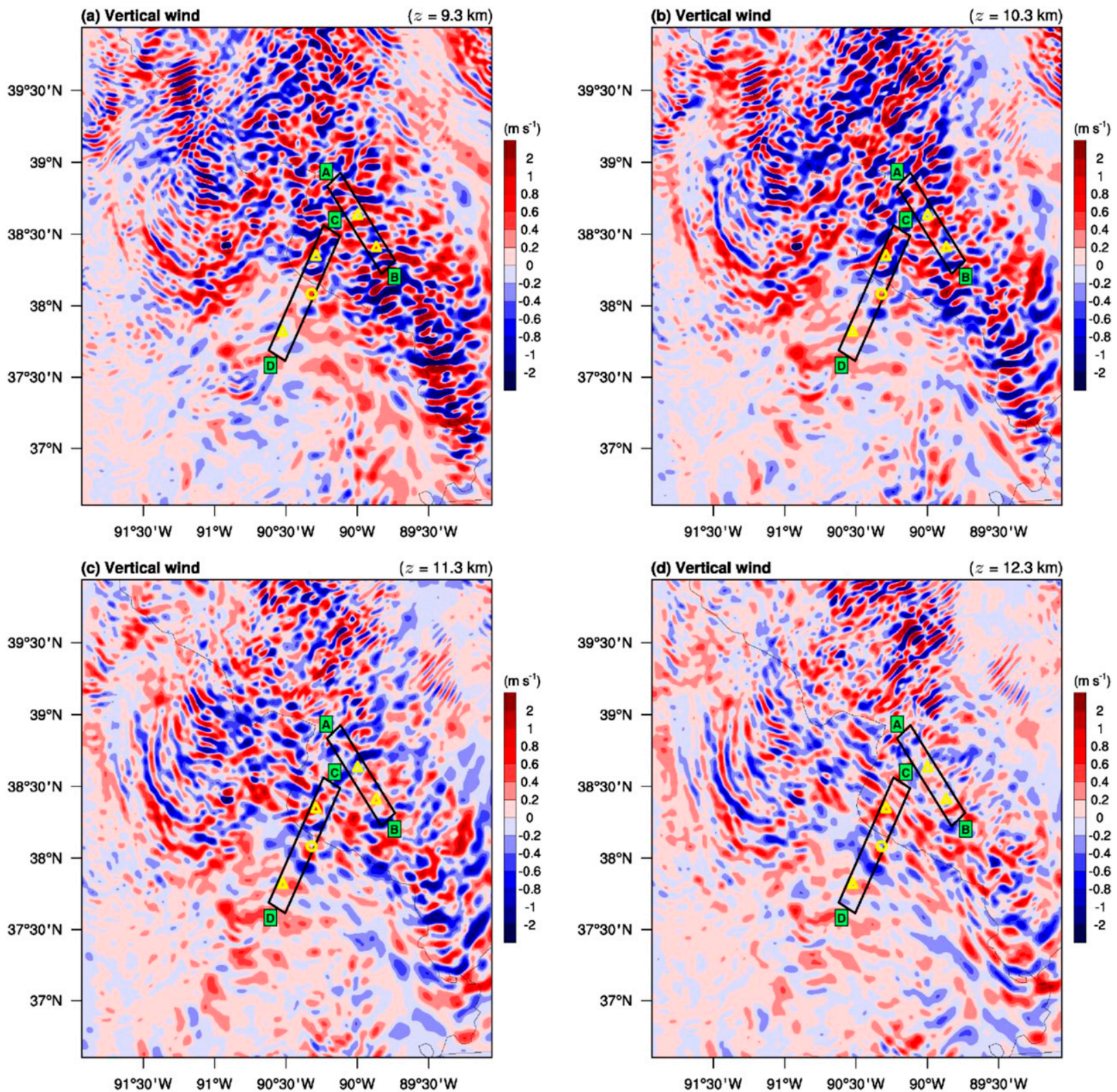

FIG. 3. Simulated vertical velocity interpolated to altitudes $(9.3,10.3,11.3$, and $12.3 \mathrm{~km})$ in D4 at 0000 UTC 10 Mar with moderate (triangle) and severe (circle) turbulence reports.

waves and their breaking are not simulated (not shown). In the left box region, the turbulence characterized by subgrid-scale TKE from the PBL scheme is simulated, but it is not matched with the observed turbulence locations (2339 UTC 9 March and 0010 and 0011 UTC 10 March). Given that PIREPs often contain discrepancies in time and location of real turbulence encounters (Schwartz 1996; Sharman et al. 2014), vertical cross sections of different time steps for the right rectangular region (from 2330 to 2344 UTC 9 March) and for the left rectangular region (from 2334 UTC 9 March to
0010 UTC 10 March) are examined and shown in Figs. 4 and 5.

From 2330 to 2344 UTC 9 March (Fig. 4), the wavy motions are found both near $(z=6-8 \mathrm{~km})$ and far from $(z=10-12 \mathrm{~km})$ the cloud boundaries. The isentropes steepen and overturn $(z=10-13 \mathrm{~km}$ and $0<x<25 \mathrm{~km})$ around 2332 UTC 9 March, leading to small-scale mixing process characterized by the expansion of the isentropes between 2330 and 2332 UTC 9 March. A similar situation is found at later times from 2334 to 2340 UTC 9 March. The amplified and steepening 

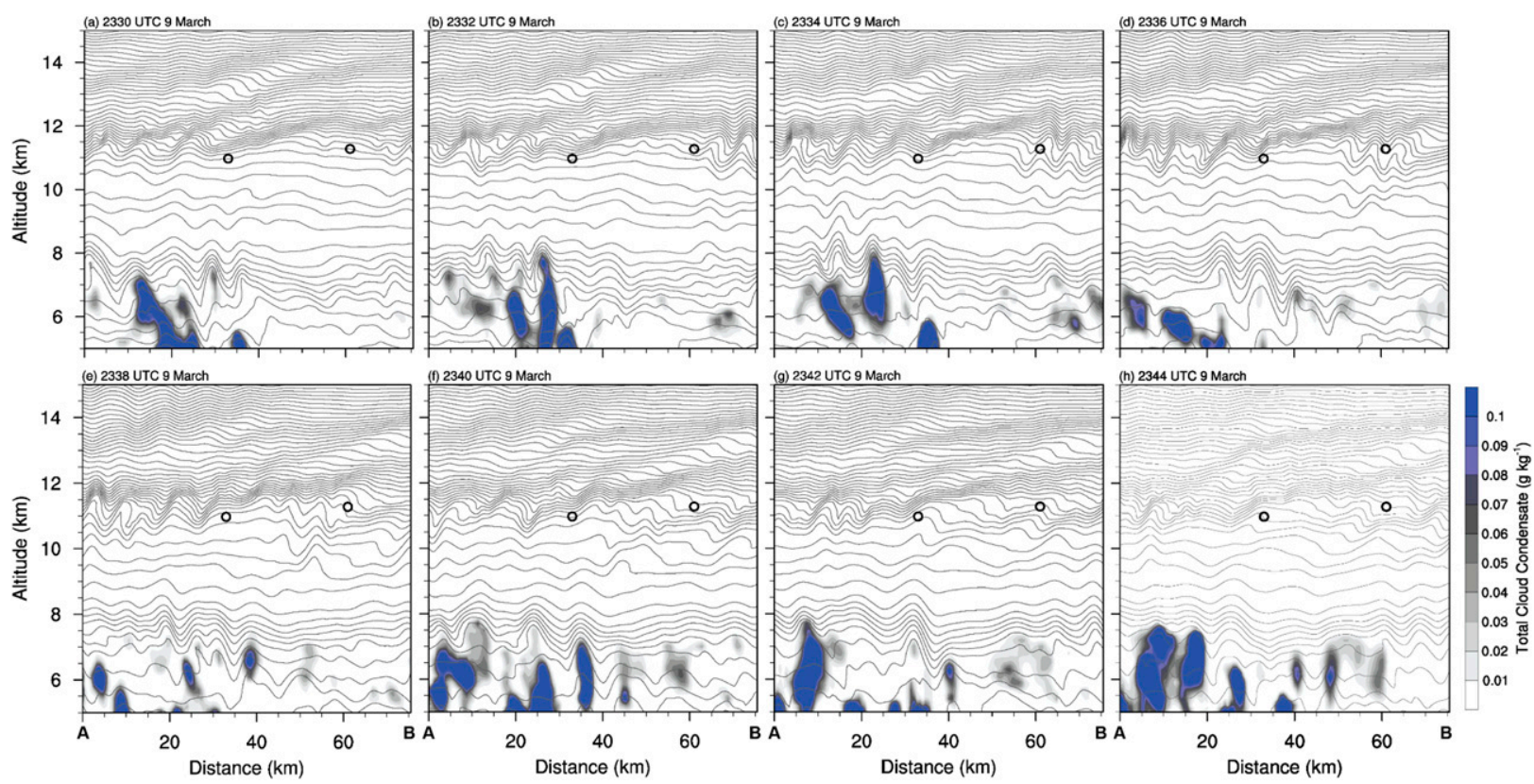

FIG. 4. Vertical cross sections of the right rectangular (marked by A-B) region in Fig. 3 for the total cloud condensate ( $\mathrm{g} \mathrm{kg}^{-1}$ ) and potential temperature (black contours with 2-K intervals) obtained from D4 for 2330-2344 UTC 9 Mar. Horizontal locations of moderate (black circle) turbulence reports are indicated.

isentropes coincide with the leftmost MOD-intensity turbulence location $(x=32.98 \mathrm{~km})$ from 2342 to 2344 UTC 9 March. The rightmost MOD-intensity turbulence $(x=$ $60.99 \mathrm{~km})$ is located close to the amplified isentropes from 2332 to 2336 UTC 9 March.

Wavy patterns are more evident between 2334 UTC 9 March and 0010 UTC 10 March (Fig. 5). Near the rightmost MOD-intensity turbulence event $(x=89.49 \mathrm{~km})$, overturning or amplification of GWs is not observed. The SEV-intensity turbulence $(x=55.59 \mathrm{~km})$ is located in the region of amplifying isentropes, evident at 2334 and 2338 UTC 9 March $(z=10.5-12 \mathrm{~km})$. At 2334 UTC 9 March, there are steepened isentropes near the leftmost MOD-intensity turbulence location $(x=27.20 \mathrm{~km})$ and a larger distance between two adjacent isentropes appears $(z=10-13 \mathrm{~km}$ and $30<x<40 \mathrm{~km})$ because of wave
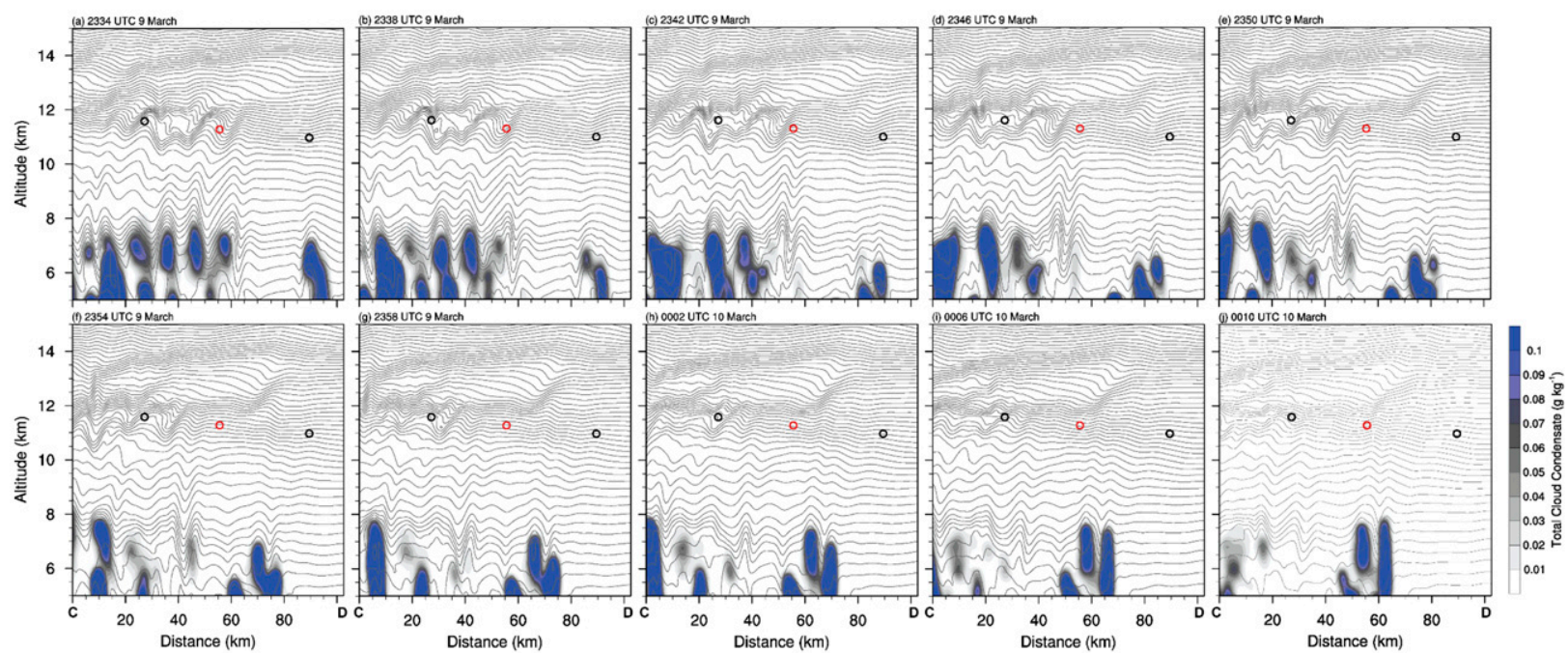

FIG. 5. Vertical cross sections of the left rectangular (marked by C-D) region in Fig. 3 for the total cloud condensate $\left(\mathrm{g} \mathrm{kg}^{-1}\right)$ and potential temperature (black contours with 2-K intervals) obtained from D4 for 2334 UTC 9 Mar to 0010 UTC 10 Mar. Horizontal locations of moderate (black circle) and severe (red circle) turbulence reports are indicated. 
breaking and turbulent mixing. Ahead of SEV-intensity turbulence location $(35<x<50 \mathrm{~km})$ between 2342 and 2346 UTC 9 March, the near vertical isentropes almost overturn and breakdown, accompanied with turbulent mixing. At the later times (between 2350 UTC 9 March and 0006 UTC 10 March), additional overturning and breaking occur near the leftmost MOD-intensity turbulence location.

Figure 6 shows the power spectral density (PSD) of the area-averaged vertical velocity along the southwestnortheast lines in the left and right rectangular regions shown in Fig. 3 with respect to the horizontal wavelength $(2 \pi /|k|$, where $k$ is a horizontal wavenumber) at $z=$ $11.3 \mathrm{~km}$ averaged between 2330 and 2344 UTC 9 March (Fig. 6a) and between 2334 UTC 9 March and 0010 UTC 10 March (Fig. 6b), by performing a fast Fourier transform. For reference, a red noise line at the $95 \%$ significance level is included (Gilman et al. 1963). Waves have significant power above the red noise line at horizontal wavelengths ranging from 3.1 to $25.2 \mathrm{~km}$ (Fig. 6a) and from 5.7 to $25.6 \mathrm{~km}$ (Fig. 6b). The spectral peaks less than $5 \Delta x(\sim 3.4 \mathrm{~km})$, where the rapid reduction in power is revealed, might be spurious signal, considering that the horizontal grid spacing of D4 shown in Fig. 3 is $0.67 \mathrm{~km}$, according to previous studies on the effective model resolution (Skamarock 2004; Skamarock et al. 2014). The waves with horizontal wavelengths between approximately 4 and $7 \mathrm{~km}$ have significant power, which are not evident in Figs. 4 and 5, while those with horizontal wavelengths between approximately 10 and $25 \mathrm{~km}$, which are seen in Figs. 4 and 5 , have also significant power. It is considered that some CGWs with these horizontal wavelengths are breaking, which influences turbulence generation.

CGWD and $\mathrm{Ri}_{\min }$ are calculated using the convective heating rate $(\mathrm{CHR})$ and cloud-top-height variables. In the original CGWD parameterization by Chun and Baik (1998), which has been used for GCMs, the CHR and cloud-top information was obtained from the cumulus parameterization scheme. In the current numerical simulation using the WRF model, both cumulus parameterization and microphysics schemes are invoked simultaneously in some coarse-resolution domains (D1 and D2 for both turbulence cases). In the present study, the cloud-top height is defined by the total cloud condensate, which aggregates cloud water, cloud ice and snow mixing ratio, with a threshold of $0.01 \mathrm{~g} \mathrm{~kg}^{-1}$. For simplicity, the cloud-top height derived from the microphysics scheme is used rather than the cloud-top height from the cumulus parameterization.

To examine the feasibility of the proposed NCT diagnostics for the turbulence observed near 0000 UTC 10 March, the eight NCT diagnostics (four CGWD-based and four $\mathrm{Ri}_{\text {min }}$-based NCT diagnostics) are calculated in D1, D2, and D3 and compared with the observed NCT
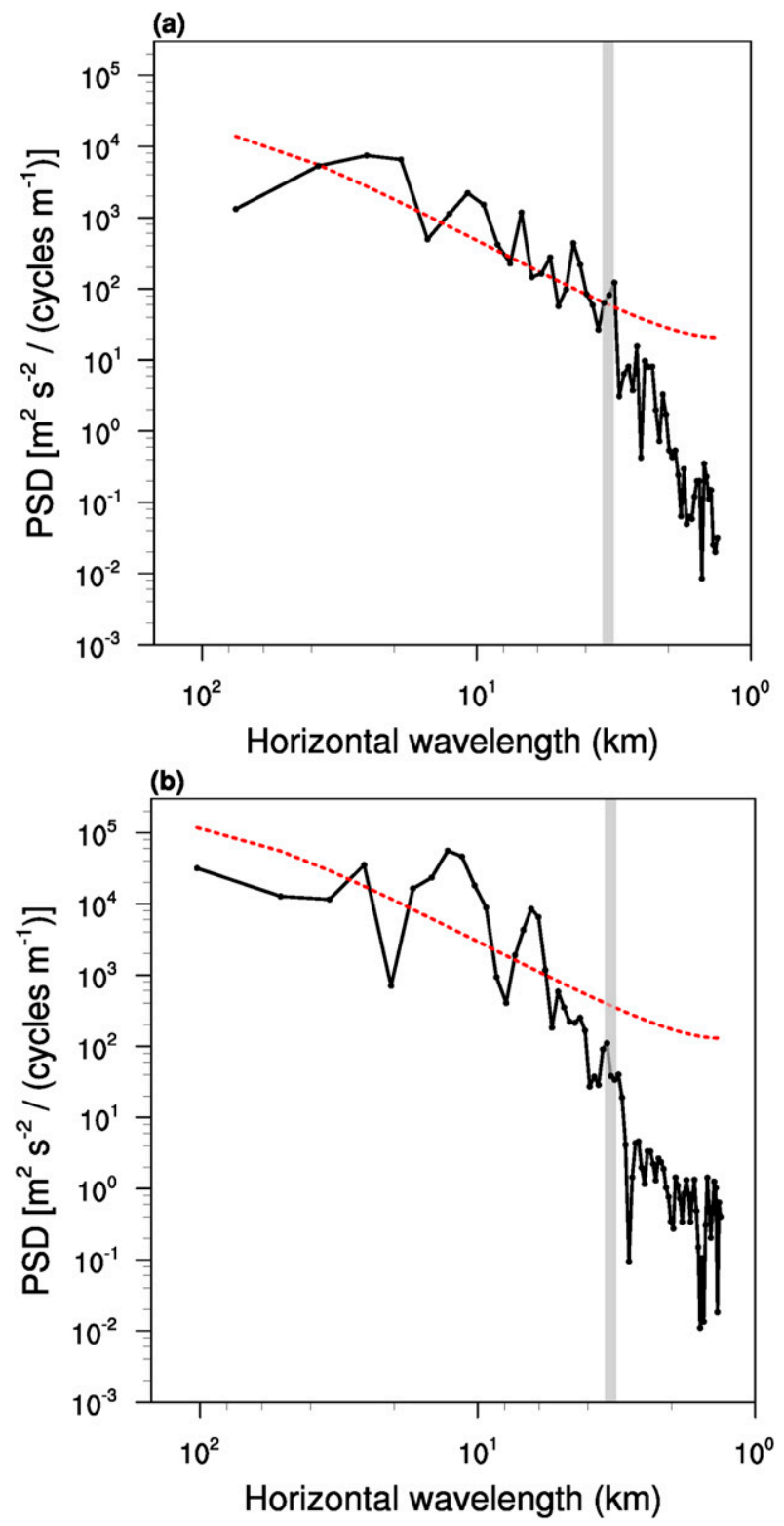

FIG. 6. The power spectrum density functions (PSDs) of the vertical wind at $z=11.3 \mathrm{~km}$ averaged over the (a) right and (b) left rectangular region in Fig. 3 averaged between 2330 and 2344 UTC 9 Mar and between 2334 UTC 9 Mar and 0010 UTC 10 Mar, respectively. The $95 \%$ red noise significance level of vertical wind is indicated by the dashed red curves and vertical reference line (gray shaded) indicates a horizontal reference scale $(5 \Delta x)$.

cases. Note that the horizontal resolutions of the three domains are similar to those of operational NWP models (e.g., Benjamin et al. 2016; Walters et al. 2017; see also http://web.kma.go.kr/eng/biz/forecast_02.jsp; http://www.emc.ncep.noaa.gov/GFS/doc.php). Figure 7 shows vertical cross sections of the CGWD-based NCT diagnostics along transect W-E of Fig. 2d in D1, D2, and D3 at 0000 UTC 10 March. The nonzero CGWD 


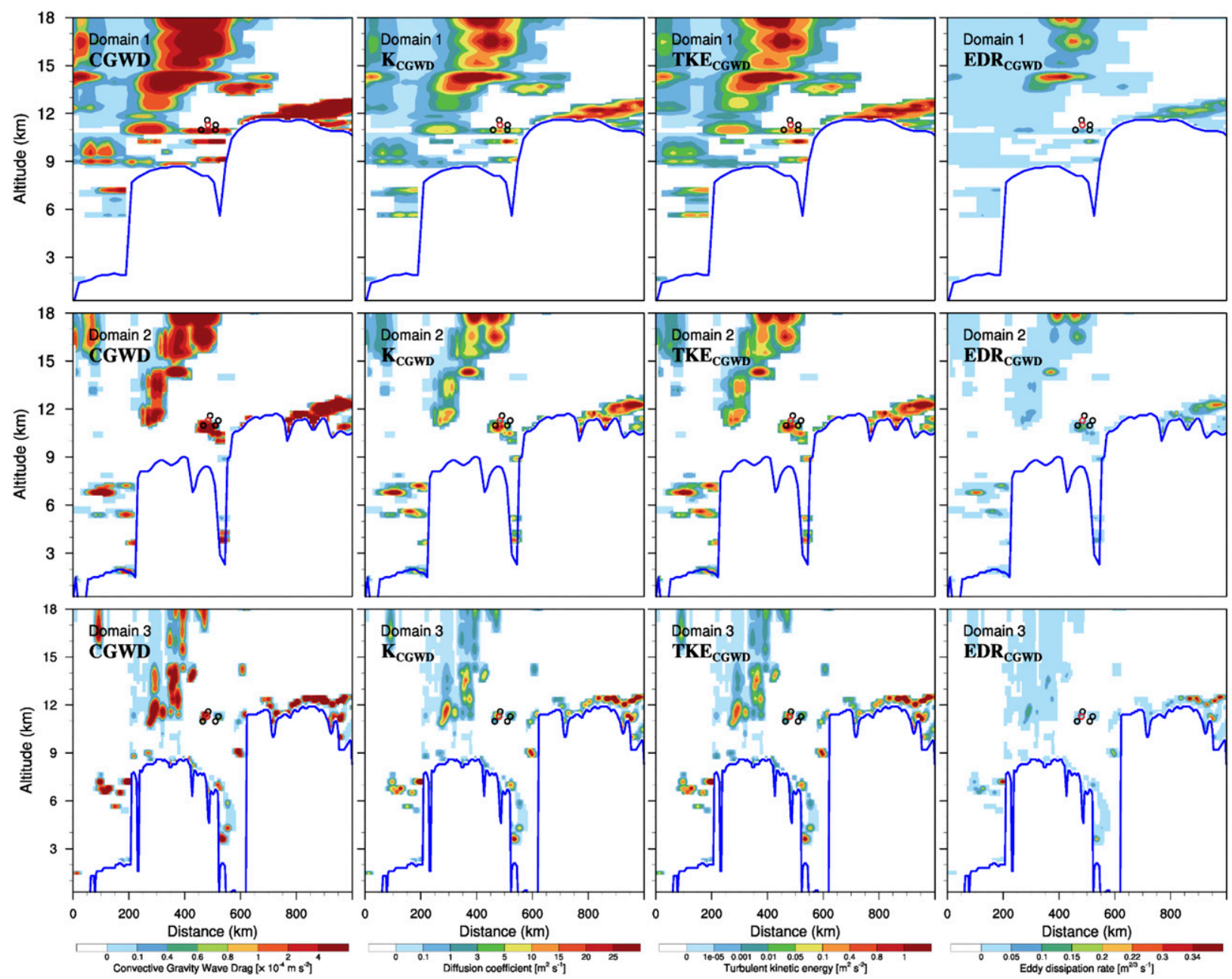

FIG. 7. Vertical cross sections for four CGWD-based NCT diagnostics in D1, D2, and D3 along transect W-E of Fig. 2d with the locations of moderate (black circle) and severe (red circle) NCT events and total cloud condensate (contour; $0.01 \mathrm{~g} \mathrm{~kg}^{-1}$ ) at $0000 \mathrm{UTC}$ 10 Mar.

exists in the regions far above the shallow convection $(x=\sim 200-400 \mathrm{~km})$ and near the deep convection boundaries $(x=\sim 700-1000 \mathrm{~km})$, although the nonzero CGWD has different spatial extents in each domain. The locations of MOG turbulence are well matched with the nonzero CGWD-based NCT diagnostics in each domain. Considering that the criteria of light (LGT), MOD, and SEV-intensity turbulence are 0.15 , 0.22 , and $0.34 \mathrm{~m}^{2 / 3} \mathrm{~s}^{-1}$ of EDR for medium-sized aircraft (Sharman and Pearson 2017), the overall resultant $\mathrm{EDR}_{\mathrm{CGWD}}$ near the turbulence incident region is between 0.05 and $0.15 \mathrm{~m}^{2 / 3} \mathrm{~s}^{-1}$, categorized as null (NIL) intensity; some regions are between 0.15 and $0.2 \mathrm{~m}^{2 / 3} \mathrm{~s}^{-1}$, categorized as LGT intensity. Considering that the subgrid-scale TKE from the PBL scheme is not matched with the turbulence regions (not shown), it is noteworthy that the regions of nonzero EDRCGWD are relatively well matched with the reported turbulence regions, despite the small value compared with the current severity threshold values.

As the model resolution is enhanced, magnitudes of the NCT diagnostics proposed in the current study generally become larger because of the increased CHR and the cloudtop momentum flux (CTMF). For the case of 9-10 March 2006, CHR is slightly larger in D3 than in D2, as expected, but CTMF is slightly smaller in D3. This is because static stability and basic-state wind speed at the cloud-top altitude, which are inversely proportional to CTMF, are larger in D3 than in D2. This implies that the simulated background condition at each model resolution can affect the resulting NCT diagnostics, together with the magnitude of CHR.

Figure 8 shows vertical cross sections that are the same as in Fig. 7 except for the $\mathrm{Ri}_{\text {min }}$-based NCT diagnostics. Although CGWD-based NCT diagnostics exist only where CGWs are breaking, the $\mathrm{Ri}_{\text {min }}$-based NCT diagnostics can exist originally at all levels above the 


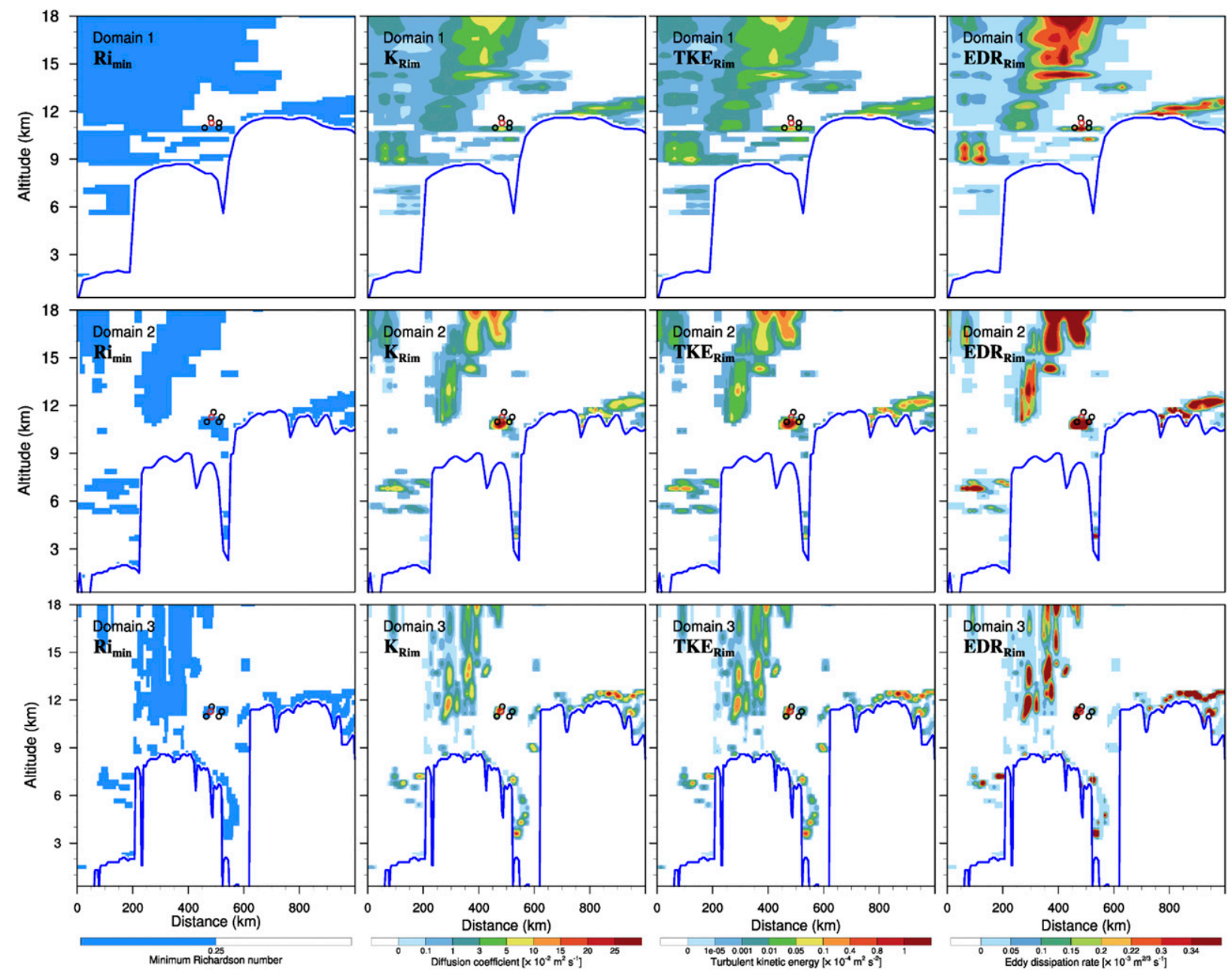

FIG. 8. As in Fig. 7, but for the $\mathrm{Ri}_{\text {min }}$-based NCT diagnostics. For easier visualization, $K_{\mathrm{Rim}}, \mathrm{TKE}_{\mathrm{Rim}}$, and EDR $\mathrm{Rim}$ are multiplied by 100 , 10000 , and 1000, respectively.

cloud-top height. However, in this study, the $\mathrm{Ri}_{\text {min }}$-based NCT diagnostics are considered only where wave breaking occurs, which is the same region of nonzero CGWD-based NCT diagnostics. Compared with Fig. 7, however, the magnitudes of $K_{\text {Rim }}, \mathrm{TKE}_{\text {Rim }}$, and EDR $\mathrm{Eim}_{\text {Rim }}$ are much smaller than $K_{\mathrm{CGWD}}$, TKE $\mathrm{CGWD}_{\mathrm{CG}}$, and $\mathrm{EDR}_{\mathrm{CGWD}}$, respectively, with more than two-order of magnitude difference. Given that the values of EDR $_{\text {CGWD }}$ are on the same order of magnitude as the reported turbulence intensity, $\mathrm{EDR}_{\text {Rim }}$ is likely two orders of magnitude smaller than the observed value. This implies that the NCT diagnostics derived from CGWD might be a valuable addition, while those derived from $\mathrm{Ri}_{\text {min }}$ are not, at least in the current case.

\section{b. 2 September 2007}

Figure 9 shows the simulated horizontal wind and geopotential height at $300 \mathrm{hPa}$ in D1 at $1200 \mathrm{UTC}$ and simulated weather radar reflectivity with horizontal wind and geopotential height at $300 \mathrm{hPa}$ in $\mathrm{D} 2$ at 1030 UTC. The current simulation indicates the prevailing westerly and southwesterly flows, which are consistent with the observed synoptic-scale features including a highly curved trough and a southerly jet shown in Kim and Chun (2012a, their Fig. 6a). Given that the southwesterly flows over the turbulence region are well simulated, the current simulation results are feasible to evaluate our proposed NCT diagnostics. The upper-level southwesterly flows at 1030 UTC (Fig. 9b) are more apparent than those at 1200 UTC (Fig. 9a). The simulated cloud bands in D2 at 1030 UTC, which is a time close to the incident time, are located along the cold front and are less widespread, but intense convection is located ahead of the front where the turbulence was encountered. The simulation result is similar to the satellite image of Fig. 8a from Kim and Chun (2012a). Although there are discrepancies in the 

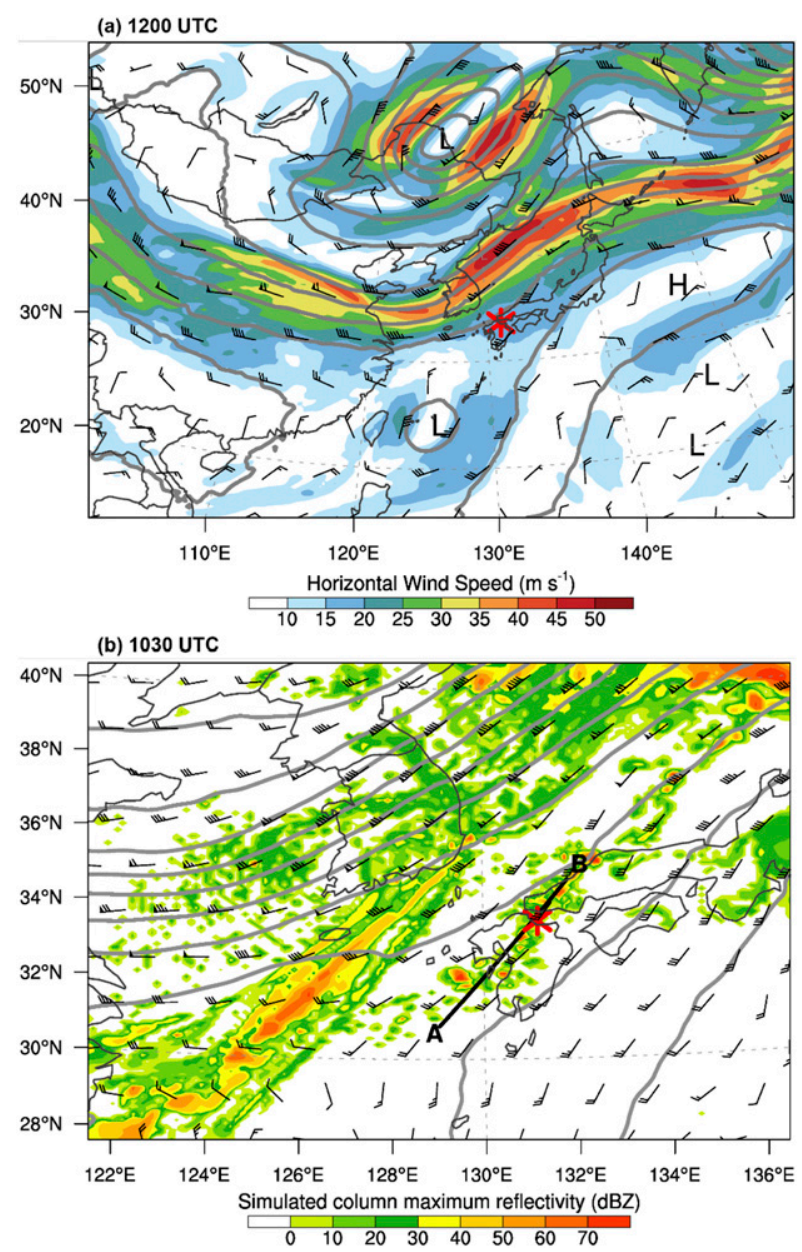

FIG. 9. (a) Simulated horizontal wind speed (shading) and direction (wind barbs) and geopotential height (contour) at $300 \mathrm{hPa}$ in D1 at 1200 UTC 2 Sep and (b) simulated column-maximum reflectivity (shading) with horizontal wind (wind barbs) and geopotential height (contour) at $300 \mathrm{hPa}$ in D2 at 1030 UTC 2 Sep. Contour intervals in (a) and (b) are 60 and 30 gpm, respectively. The horizontal location of a severe turbulence encounter is depicted as an asterisk.

details compared with the observations, the simulation results agree well with the time, location, and overall features, together with the upper-level large-scale features.

Figure 10 shows the vertical velocity interpolated to four altitudes $(z=9.2,10.2,11.2$, and $12.2 \mathrm{~km})$ in $\mathrm{D} 4$ at 1034 UTC. Vigorous simulated upward motion occurs at the lowest two levels shown in regions just to the southwest of the turbulence location. At higher altitudes $(11.2$ and $12.2 \mathrm{~km})$, the vertical motions are weakened, which is particularly apparent near the location of the turbulence report, and this may be due to wave breaking and small-scale mixing. To examine the evolution of the vertical structure of the convection, vertical cross sections are constructed using the total cloud condensate and potential temperature along transect C-D of Fig. 10 at selected times of 0900, 0930, 1000, and 1030 UTC (Fig. 11).

At 0900 UTC (Fig. 11a), two updrafts penetrating the tropopause to about $z=12.5$ and $13.5 \mathrm{~km}$ are located about $50 \mathrm{~km}$ away $(10<x<50 \mathrm{~km})$ from the turbulence region and convectively generated GWs propagate vertically to higher altitudes. Above the cloud boundaries, the steepening isentropes are clearly revealed and some GWs are overturning. From 0930 to 1000 UTC (Figs. 11b,c), the convection in the mature stage is advected with the prevailing southwesterly flows and the cloud thicknesses noticeably reduce. Eventually, at 1030 UTC (Fig. 11d), which is a time close to the incident time, the convection is in the dissipating stage. However, the overturning of CGWs is not indicated near the turbulence region in D4 at 1030 UTC. The vertical cross sections are constructed using the nonzero subgrid-scale TKE from the PBL scheme, total cloud condensate, and potential temperature obtained from the finer domain (D6) for the inner box in Fig. 11d and are shown in Fig. 12. From 1033 to 1036 UTC (Fig. 12), the isentropes above the dissipated convection ahead of the turbulence location start to steepen as the convection moves toward the turbulence region. Eventually, between 1035 and 1036 UTC, overturning of GWs and nonzero subgrid-scale TKE are revealed in the turbulence incident region $(x=20 \mathrm{~km})$ about $1-2 \mathrm{~km}$ above the cloud interface.

Figure 13 shows the PSD of the vertical velocity in the region of Fig. 12 with horizontal grid spacing of $0.123 \mathrm{~km}$ with respect to the horizontal wavelengths at $z=11.2 \mathrm{~km}$ averaged between 1033 and 1036 UTC. As in Fig. 6, the red noise line at the $95 \%$ significance level is included for reference. The waves have significant powers above the red noise line at horizontal wavelengths ranging from 2 to $13 \mathrm{~km}$. The effective resolution is around $12 \Delta x$ $(\sim 1.48 \mathrm{~km})$, where the substantial reduction in power is exhibited, considering that the horizontal grid spacing of D6 is $0.123 \mathrm{~km}$. A dominant peak appears at the horizontal wavelengths between 6.5 and $13 \mathrm{~km}$ and second peak appears at the horizontal wavelengths around 4 and $2 \mathrm{~km}$ where the CGWs are relevant, although they are not evident in Figs. 11 and 12. It is considered that some of waves with these significant horizontal wavelengths are breakdown.

Figure 14 shows vertical cross sections of the total cloud condensate along transect A-B of Fig. 9b in D1, D2, and D3 at 1025 UTC to identify the cloud boundaries in each domain. Considering that this turbulence case clearly occurred above the dissipated convection (Kim and Chun 2012a), the reported turbulence event is located within the cloud boundary or in-cloud region in D1 (Fig. 14a) where the simulated total cloud condensate is between 0.06 and $0.08 \mathrm{~g} \mathrm{~kg}^{-1}$ because of a coarser 
(a) Vertical wind

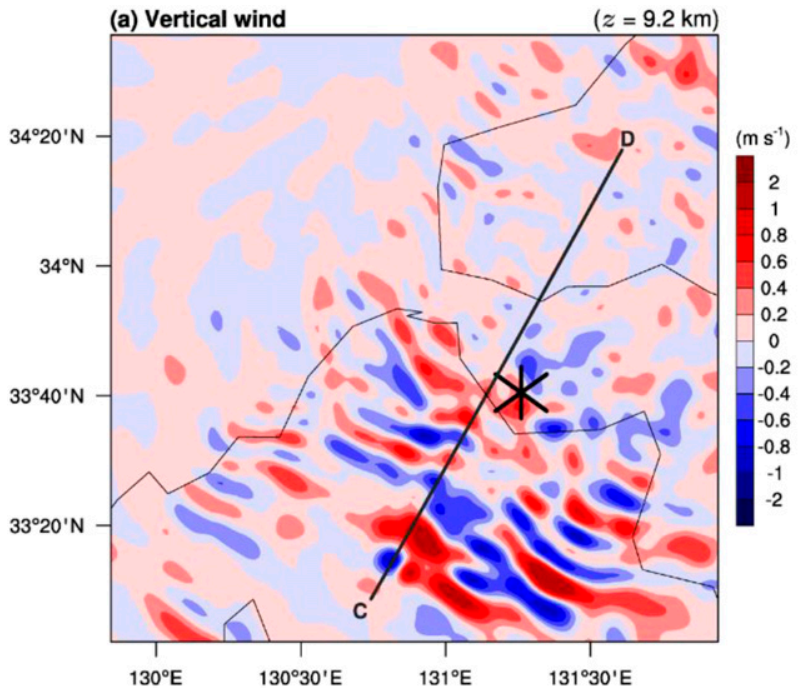

(c) Vertical wind

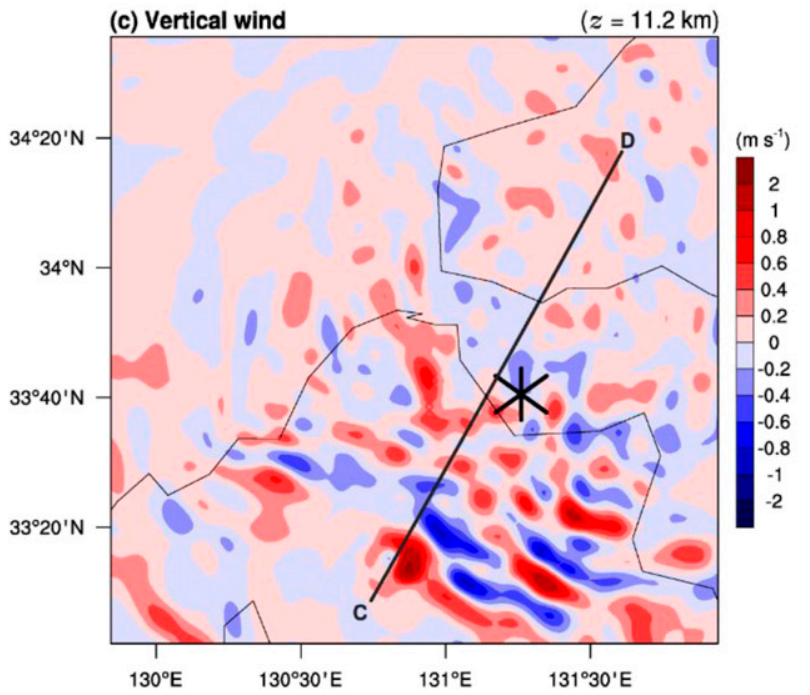

(b) Vertical wind
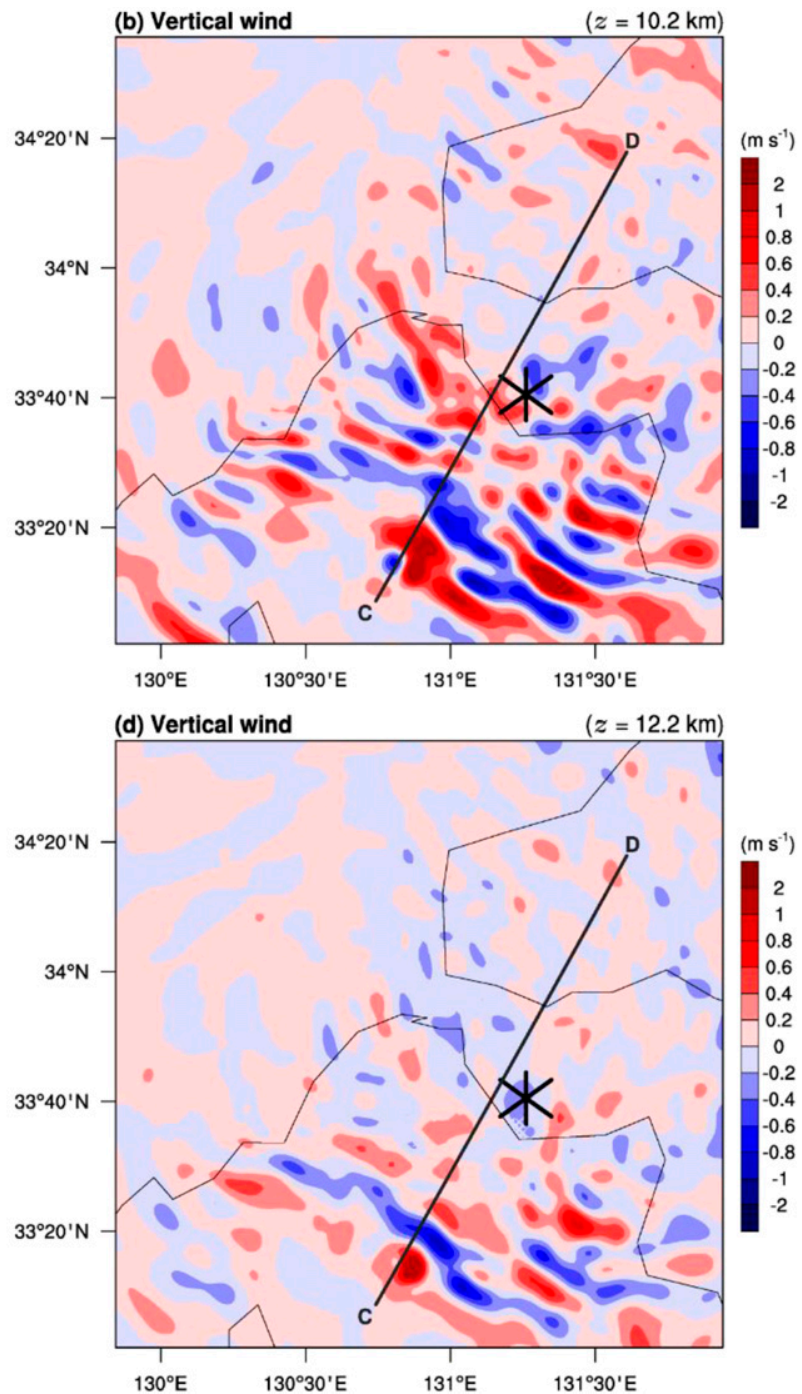

FIG. 10. Simulated vertical velocity interpolated to altitudes $(9.2,10.2,11.2$, and $12.2 \mathrm{~km})$ in D4 at 1034 UTC 2 Sep with severe (asterisk) turbulence encounter.

resolution. Therefore, the simulated results of D2 and D3 (Figs. 14b,c) will be used in calculating eight NCT diagnostics, instead of D1 (Fig. 14a). The cloud-top height is determined using the same approach used in section $4 \mathrm{~b}$, except for the total cloud condensate with a threshold of $0.05 \mathrm{~g} \mathrm{~kg}^{-1}$.

Figure 15 shows vertical cross sections of the CGWDbased NCT diagnostics in D2 and D3 at 1025 UTC along the same transect as that used for Fig. 14. At the turbulence incident time (1034 UTC), there is no CGWD near the turbulence incident region (not shown). However, at a time earlier than the incident time (1025 UTC), nonzero CGWD is revealed both near and far above the cloud boundary in the deep convection $(x<$ $30 \mathrm{~km}$ ). The location of SEV turbulence is well matched with the nonzero CGWD-based NCT diagnostics in each domain. The overall resultant $\mathrm{EDR}_{\mathrm{CGWD}}$ near the turbulence incident region in D2 is between 0.15 and $0.2 \mathrm{~m}^{2 / 3} \mathrm{~s}^{-1}$, which is categorized as LGT intensity and that in D3 is between 0.22 and $0.34 \mathrm{~m}^{2 / 3} \mathrm{~s}^{-1}$, which is categorized as MOG intensity for midsized aircraft (Sharman and Pearson 2017). It is noteworthy that the NCT diagnostics related to wave breaking are well matched with the NCT event above the dissipated convection as well. In the two turbulence events, the length scale in the denominators of (9) and (10) is set to the vertical grid spacing for each simulation $(\sim 240 \mathrm{~m}$ for 9-10 March 2006 and $100 \mathrm{~m}$ for 2 September 2007). Considering that the resulting EDR CGWD $_{\text {in Figs. } 7 \text { and }}$ 8 is less than $0.15 \mathrm{~m}^{2 / 3} \mathrm{~s}^{-1}$, it is possible that the length scale considerably affects the difference in the magnitudes of TKE $\mathrm{CGWD}_{\mathrm{D}}$ and $\mathrm{EDR}_{\mathrm{CGWD}}$. 

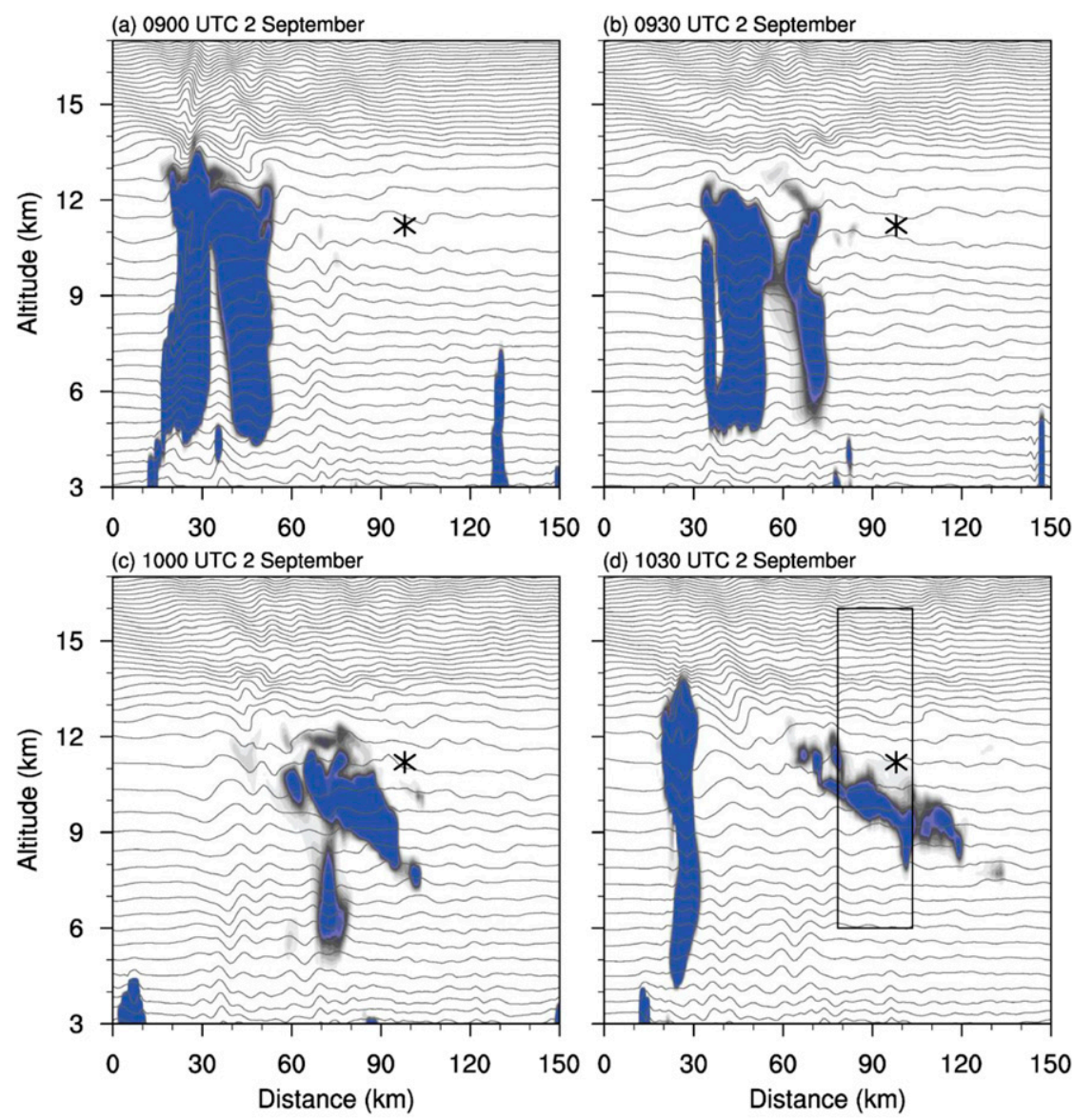

(d) 1030 UTC 2 September

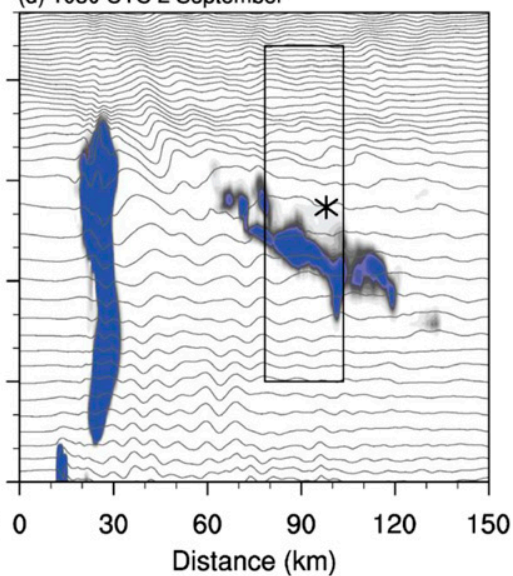

Total Cloud Condensate $\left(\mathrm{g} \mathrm{kg}^{-1}\right.$

0.010 .020 .030 .040 .050 .060 .070 .080 .090 .1

FIG. 11. Vertical cross sections of total cloud condensate (shading; $\mathrm{g} \mathrm{kg}^{-1}$ ) and potential temperature (black contours with $2-\mathrm{K}$ intervals) obtained from $\mathrm{D} 4$ along transect $\mathrm{C}-\mathrm{D}$ of Fig. 10 from 0900 to 1030 UTC 2 Sep. The horizontal location of the severe turbulence encounter (asterisk) is indicated.

Figure 16 shows vertical cross sections that are the same as those of Fig. 15 except they display the $\mathrm{Ri}_{\text {min }^{-}}$ based NCT diagnostics, instead of the CGWD-based NCT diagnostics. As in Fig. 8, the $\mathrm{Ri}_{\text {min }}$-based NCT diagnostics are considered only at the level of wave breaking. The resultant EDR $_{\text {Rim }}$ is somewhat small and is categorized as NIL-intensity turbulence, considering that the criterion of NIL-intensity turbulence is $0.15 \mathrm{~m}^{2 / 3} \mathrm{~s}^{-1}$ (Sharman and Pearson 2017). Compared with Fig. 15, the magnitudes of $K_{\text {Rim }}, \mathrm{TKE}_{\text {Rim }}$, and $\mathrm{EDR}_{\text {Rim }}$ are much smaller than $K_{\mathrm{CGWD}}$, TKE $\mathrm{CGWD}_{\mathrm{C}}$, and $\mathrm{EDR}_{\mathrm{CGWD}}$, respectively, with a difference of more than two orders of magnitude, as is also shown in Figs. 7 and 8. Given that the values of $E_{\text {DDR }}$ Core of LGT- and MOG-intensity severity in $\mathrm{D} 2$ and $\mathrm{D} 3$, the NCT diagnostics derived from CGWD might be more useful for turbulence forecasts than those from $\mathrm{Ri}_{\min }$. The difference between EDRs derived from CGWD and $\mathrm{Ri}_{\min }\left(\mathrm{EDR}_{\mathrm{CGWD}}\right.$ and EDR $\left._{\text {Rim }}\right)$ results from how the diffusion coefficients ( $K_{\mathrm{CGWD}}$ and $K_{\mathrm{Rim}}$ ) are calculated. We do not currently know why EDR based on CGWD is better than that based on $\mathrm{Ri}_{\text {min }}$ for the two NCT cases considered. This aspect requires further investigations wherein a greater number of observed NCT cases are considered.

The CAT diagnostics, which are routinely included in operational forecasting systems, have been assumed to follow the lognormal distributions (e.g., Sharman and Pearson 2017). In this regard, to examine whether the probability density functions (PDFs) of the NCT diagnostics follow lognormal distributions, the PDFs and lognormal PDFs of the NCT diagnostics for two turbulence cases are computed and shown in Fig. 17. The PDFs are calculated using the NCT diagnostics between 200 and $250 \mathrm{hPa}$ for the two turbulence events (from 

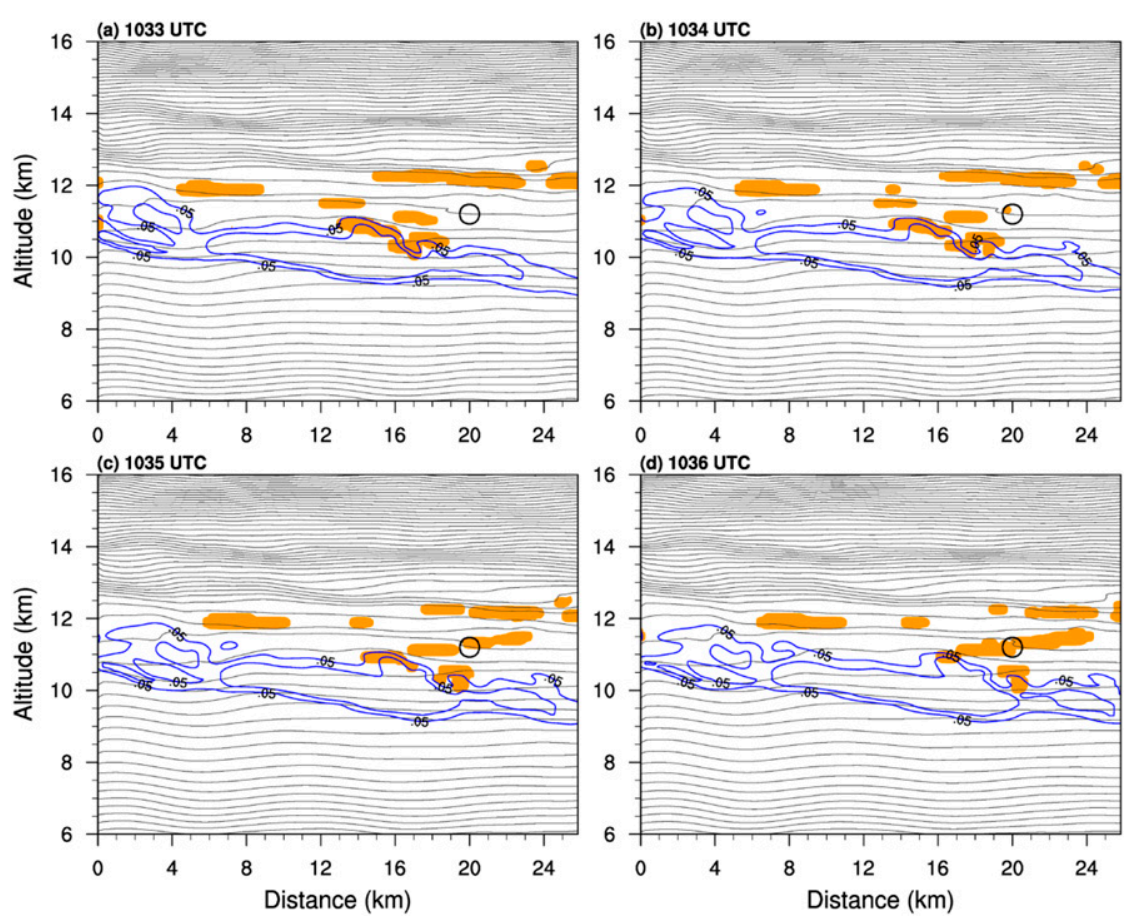

FIG. 12. Vertical cross sections of subgrid-scale TKE (shading $>0.1 \mathrm{~m}^{2} \mathrm{~s}^{-2}$ ) with total cloud condensate (blue contours; 0.05 and $0.1 \mathrm{~g} \mathrm{~kg}^{-1}$ ) and potential temperature (black contours with 1-K intervals) obtained from D6, which corresponds to the inner rectangle in Fig. 11d at (a) 1033, (b) 1034, (c) 1035, and (d) 1036 UTC 2 Sep. The horizontal location of the severe turbulence encounter is indicated by the circle.

2300 UTC 9 March to 0100 UTC 10 March 2006 and from 0900 to 1100 UTC 2 September 2007) for the domain with $10-\mathrm{km}$ horizontal grid spacing (indicated in Fig. 1), which itself is consistent with typical resolutions of current NWP models. The lognormal PDF is computed with the standard deviation and mean of the natural logarithms of each diagnostics (Wilks 1995). It is noted that the PDFs of $\mathrm{Ri}_{\text {min }}$, which have both negative and positive value, are not considered because of the natural logarithms. When the PDFs of all NCT diagnostics for two turbulence events are computed using the data with nonzero and zero NCT diagnostics, the values of the PDFs are more than 0.99 within the first interval for each NCT diagnostics (not shown). Therefore, in Figs. 17 and 18, we calculate the PDFs of nonzero NCT diagnostics exclusively. The 95th and 99th percentiles of CGWD on both 9-10 March 2006 and 2 September 2007 are about $0.35 \times$ $10^{-4} \mathrm{~m} \mathrm{~s}^{-2}\left(=3.02 \mathrm{~m} \mathrm{~s}^{-1} \mathrm{day}^{-1}\right)$ and $0.43 \times 10^{-4} \mathrm{~m} \mathrm{~s}^{-2}$ $\left(=3.72 \mathrm{~m} \mathrm{~s}^{-1} \mathrm{day}^{-1}\right)$, respectively. The magnitude of CGWD obtained in the current study is much larger than that obtained from the GCM simulations of Chun et al. $\left(2001 ; 0.6 \mathrm{~m} \mathrm{~s}^{-1} \mathrm{day}^{-1}\right.$ at $\left.200 \mathrm{hPa}\right)$ and Chun et al. (2004; 0.59 and $0.28 \mathrm{~m} \mathrm{~s}^{-1} \mathrm{day}^{-1}$ at $200 \mathrm{hPa}$ in January and July, respectively). This difference in magnitudes is likely due to the enhanced horizontal resolution $(\Delta x=$ $10 \mathrm{~km}$ ) and large magnitude of CHR calculated at the finer grid points.

As the model resolution increases, convective updrafts become stronger and more prominent, because small-scale convective process, which was not properly resolved at a coarser model resolution, is resolved (e.g., Kim and Chun 2010). Accordingly, the magnitude of CHR increases at a finer model resolution. Because the CTMF is proportional to the square of the columnmaximum CHR, large CHR can lead to a high potential of large CTMF in general, although other factors such as static stability and basic-state wind speed also influence the magnitude of CTMF. When the CTMF increases, there is greater chance of CGWs breaking near typical commercial aviation cruising altitudes in the upper troposphere or lower stratosphere (UTLS). This contrasts with some GCM simulations, such as Chun et al. (2001), where relatively weak CHR and CTMF can lead to vertically propagating CGWs breaking mostly in the mesosphere.

For both the 9-10 March 2006 and 2 September 2007 turbulence events, the PDFs of all NCT diagnostics generally follow the lognormal distributions well, although there are underestimations or overestimations 


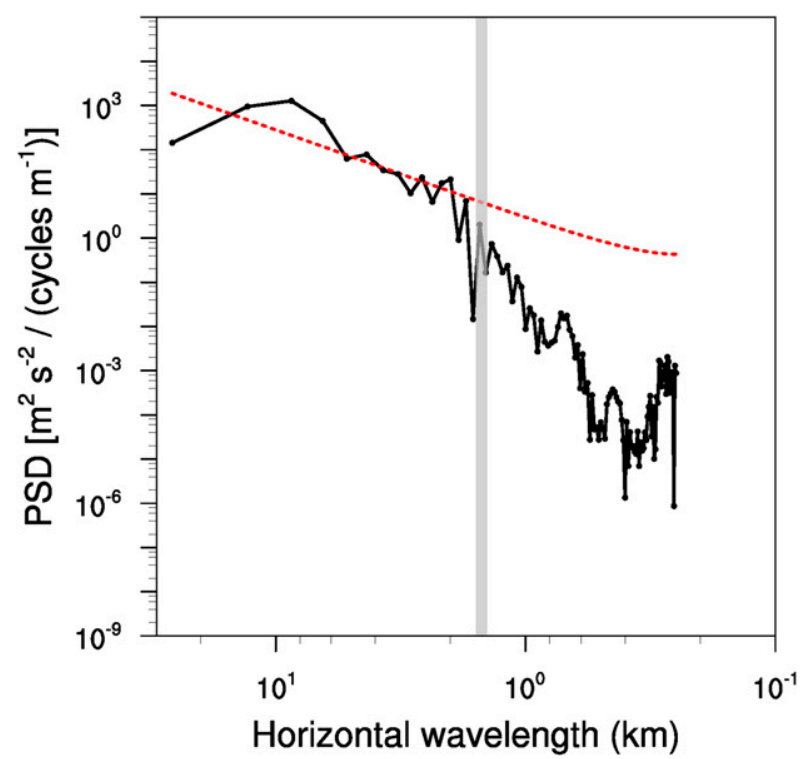

FIG. 13. The PSD of the 10.2-11.2-km vertical wind over the inner rectangle in Fig. 11d averaged between 1033 and 1036 UTC 2 Sep. The $95 \%$ red noise significance level of vertical wind is represented by the dashed red curve and vertical reference line (gray shaded) indicates a horizontal reference scale $(12 \Delta x)$.

(Fig. 17). The discrepancy between the PDFs and lognormal PDFs is generally more remarkable in the $\mathrm{Ri}_{\text {min }^{-}}$ based NCT diagnostics. Compared with the PDFs for 9-10 March 2006, the PDFs for 2 September 2007 indicate relatively large differences with lognormal PDFs. This can be related to the difference in the sizes of the domains $(1430 \mathrm{~km} \times 1460 \mathrm{~km}$ for 2 September 2007 and $4550 \mathrm{~km} \times 2540 \mathrm{~km}$ for 9-10 March 2006) with respect to the sample number.

\section{Application to the global domain}

The NCT diagnostics proposed in the current study were compared with turbulence events reported over the central U.S. and East Asia in section 4. In this section, CGWD, which is one of the NCT diagnostics, is calculated using the first version of the NCEP Climate Forecast System Reanalysis (CFSR; Saha et al. 2010) data with a $1^{\circ}$ longitude by $1^{\circ}$ latitude grid spacing from December 2009 to November 2010. For comparison, the Ellrod1 index (Ellrod and Knapp 1992), which is a widely used CAT diagnostic, is calculated using the same dataset. The Ellrod1 index is related to the upperlevel frontogenesis process and combines the total deformation and vertical wind shear [see Eq. (9) of Ellrod and Knapp 1992].

Figure 18 shows the PDFs and lognormal PDFs of nonzero CGWD and Ellrod1 index at altitudes between 200 and $250 \mathrm{hPa}$, calculated using 1-yr CFSR global reanalysis data. The PDF of nonzero CGWD generally follows the lognormal distribution, consistent with current CAT diagnostics including the Ellrod1 index. The 95th percentiles of CGWD and Ellrod1 index (blue lines in Figs. 18a,b) are $7.14 \times 10^{-7} \mathrm{~m} \mathrm{~s}^{-2}$ and $4.17 \times 10^{-7} \mathrm{~s}^{-2}$, respectively. Considering that Kim and Chun (2016) showed the percentage of MOG-intensity turbulence events were approximately $5 \%$, the 95 th percentile is used as a threshold of MOG-intensity turbulence in the current study.

The annual mean frequencies of MOG-intensity turbulence at altitudes between 200 and $250 \mathrm{hPa}$ (Figs. 18c,d), which exceeds the 95th percentiles of CGWD and Ellrod1 index reveal several interesting features. The mean wind at the same altitudes (between 200 and $250 \mathrm{hPa}$ ) is superimposed (contour) in Figs. 18c and 18d. First, relatively large frequencies of MOGintensity turbulence calculated using the Ellrod1 index occur in the Northern Hemisphere $(\mathrm{NH})$ and Southern Hemisphere $(\mathrm{SH})$ midlatitudes $\left(25^{\circ}-65^{\circ} \mathrm{N}\right.$ and $25^{\circ}-65^{\circ} \mathrm{S}$, respectively), where the major jet streams exist because the Ellrod1 index is closely related to the jet streams and frontogenesis (Fig. 18d).

In contrast, relatively large frequencies of MOGintensity turbulence calculated by CGWD occur in the tropical region $\left(25^{\circ} \mathrm{N}-25^{\circ} \mathrm{S}\right)$, where the dominant peak of $\mathrm{CHR}$ exists, and in the $\mathrm{NH}$ storm-track regions (North Pacific and Atlantic storm-track regions) and SH storm-track region (South Pacific storm-track region) in wintertime where the secondary peak of CHR exists (e.g., Kang et al. 2017). The occurrence frequencies of MOG-intensity turbulence calculated by CGWD are much lower than those using the Ellrod1 index. This is likely because convective activities are highly intermittent and nonzero CGWD exists exclusively where convectively generated GW breakdown above the convective cloud, which at any given times is likely to be less widespread than large-scale factors (e.g., jet streams) that support turbulence. The frequency of MOG-intensity turbulence calculated by CGWD at altitudes of $175 \mathrm{hPa}$ (not shown) is slightly increased than the frequency at the lower altitudes $(200-250 \mathrm{hPa})$, especially over the tropical region where the high and deep cloud exists. Nevertheless, the CGWD and other NCT diagnostics proposed in the current study (not shown) can represent NCT generations in strong convective areas, such as the tropics during most seasons, the subtropics during summertime, and midlatitude storm tracks in wintertime where most CAT diagnostics are missed in current aviation turbulence forecasting models.

It is noteworthy that the NCT diagnostics, including CGWD shown in Fig. 18, can fill in the global features of 

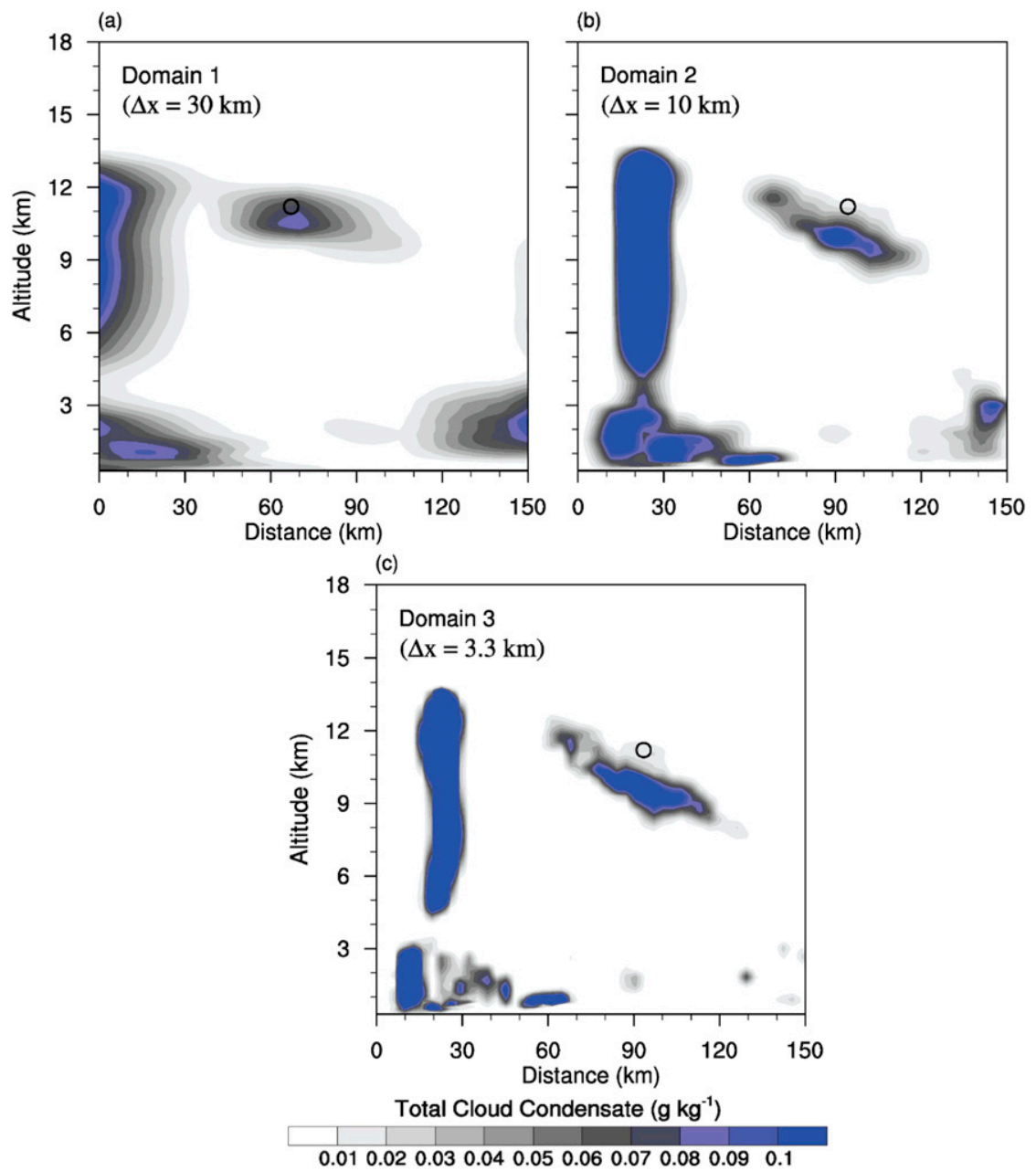

FIG. 14. Vertical cross sections in D1, D2, and D3 along transect A-B of Fig. 9b of the total cloud condensate at 1025 UTC 2 Sep. The horizontal location of the severe turbulence encounter is indicated by the circle.

aviation turbulence trends in the changed climate, which were recently reported in some studies. For example, Storer et al. (2017) investigated the global response of CAT to climate change using climate model simulations. They showed that almost all CAT diagnostics investigated could be expected to increase in magnitude for the larger values, and are mostly concentrated in the midlatitudes. The nearly no changes in aviation turbulence in the tropical region for the changed climate [Fig. 3 of Storer et al. (2017)] are due mainly to the lack of proper CAT diagnostics representing aviation turbulence in the tropical region. The NCT diagnostics proposed in the current study, which are concentrated in the tropical region for all seasons, midlatitude storm tracks in wintertime, and midlatitudes in summertime where convective clouds are activated (Fig. 18), can advance our understanding in global features of aviation turbulence and their changes in changed climate.
For turbulence forecasting and nowcasting purposes, an implementation of our proposed NCT diagnostics into the global aviation turbulence forecasting systems could potentially identify areas of NCT generation, which are missed by current CAT diagnostics. The feasibility of the NCT diagnostics proposed in the present study for use in the global aviation turbulence forecasting system will be examined in research using global in situ flight EDR data, which is under way.

\section{Summary and discussion}

In the present study, we propose four CGWD-based NCT diagnostics (CGWD, $K_{\mathrm{CGWD}}$, TKE $\mathrm{CGWD}_{\mathrm{D}}$, and EDR $\left._{\text {CGWD }}\right)$ and four $\mathrm{Ri}_{\text {min }}$-based NCT diagnostics $\left(\mathrm{Ri}_{\text {min }}, K_{\mathrm{Rim}}, \mathrm{TKE}_{\mathrm{Rim}}\right.$, and $\left.\mathrm{EDR}_{\mathrm{Rim}}\right)$ utilizing the CGWD parameterization scheme of Chun and Baik 

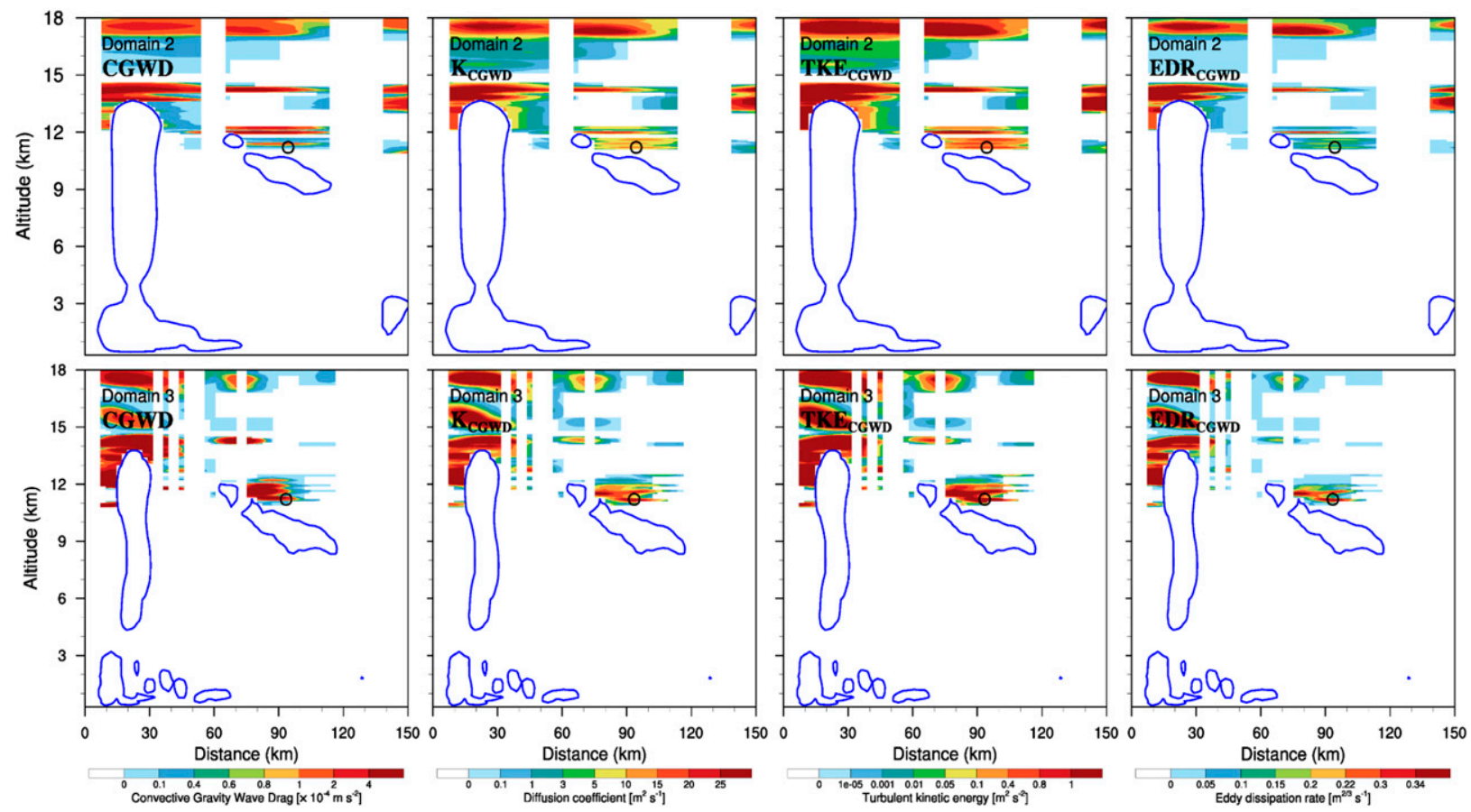

FIG. 15. Vertical cross sections for four CGWD-based NCT diagnostics in D2 and D3 along transect A-B of Fig. 10b with the location of the severe turbulence event (circle) and total cloud condensate (contour; $0.05 \mathrm{~g} \mathrm{~kg}^{-1}$ ) at $1025 \mathrm{UTC} 2 \mathrm{Sep}$.

(1998). The viability of the NCT diagnostics is examined using analysis of high-resolution WRF Model simulations for two real NCT cases reported by Trier et al. (2012) and Kim and Chun (2012a), which occurred over the central United States on 9-10 March 2006 and near Fukuoka, Japan, on 2 September 2007, respectively. Given that the two NCT cases were well simulated by Trier et al. (2012) and Kim and Chun (2012a), the same experimental configurations are used, in order to simulate their results as closely as possible, using an updated version of the WRF Model. For the observed NCT case investigated by Trier et al. (2012), the observed turbulence occurs above active shallow convection. In contrast, for the observed NCT case investigated by Kim and Chun (2012a), the relevant convection is in the dissipating phase, which originated from deep convection. The NCT diagnostics calculated in the coarser domains [three domains for Trier et al. (2012) and two domains for Kim and Chun (2012a)] coincide reasonably well with most of the observed MOG-intensity turbulence events. For the case of 9-10 March 2006, two, three, and four NCT events are well represented by our NCT diagnostics in domain 1,2, and 3, respectively, among the five observed MOG-intensity turbulence events. For the case of 2 September 2007 where only one SEV turbulence event was observed, the NCT event is well represented by our NCT diagnostics in both domains
2 and 3. For both cases, the magnitude of the CGWDbased NCT diagnostics $\left(K_{\mathrm{CGWD}}\right.$, TKE $\mathrm{CGWD}_{\mathrm{C}}$, and $\mathrm{EDR}_{\mathrm{CGWD}}$ ) is much larger than the magnitude of the $\mathrm{Ri}_{\text {min }}$-based NCT diagnostics $\left(K_{\mathrm{Rim}}, \mathrm{TKE}_{\mathrm{Rim}}\right.$, and $\left.E_{\text {Rim }}\right)$, and it is relatively close to the observed severity of turbulence. However, the magnitudes of proposed NCT diagnostics (e.g., EDR CGWD $_{\text {and }}$ EDR $\left._{\text {Rim }}\right)$ are still lower than the observed turbulence intensities. The low magnitudes revealed by the NCT diagnostics compared with the observed turbulence intensities may be related to the model resolution. Note that most turbulence diagnostics calculated using NWP model output generally underestimate the observed intensities of turbulence (e.g., Barber et al. 2018; Lee and Chun 2018). These diagnostics are often better indicators of potential locations of aviation turbulence, which was the case for the two NCT events studied in the current paper. Nevertheless, it is worthwhile examining how good the proposed NCT diagnostics compared with a large number of turbulence observations, based on the in situ flight turbulence observations, which is under way.

To calculate the NCT diagnostics proposed in the current study, CHR information is required. Although $\mathrm{CHR}$ is an important parameter as the source of waves in the CGWD parameterization, many global analysis and reanalysis datasets, and even some regional forecasts do not publicly provide CHR as a standard output. 

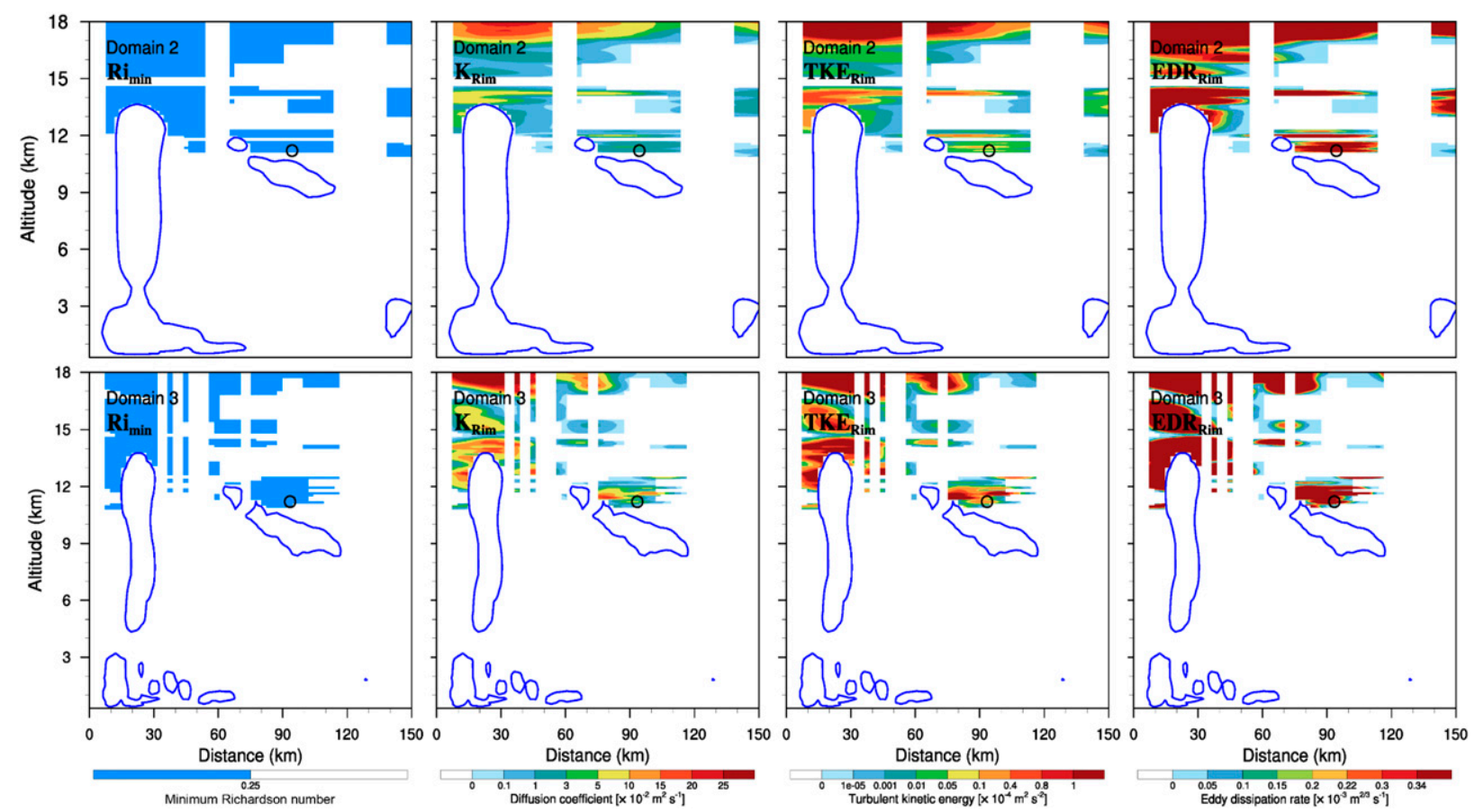

FIG. 16. As in Fig. 15, but for $\mathrm{Ri}_{\mathrm{min}}$-based NCT diagnostics. For easier visualization, $K_{\mathrm{Rim}}$, $\mathrm{TKE}_{\mathrm{Rim}}$, and EDR $\mathrm{Rim}_{\text {are }}$ multiplied by 100,10000 , and 1000 , respectively.

To complement the absence of CHR, several previous studies have attempted to derive CHR from the convective precipitation rate (e.g., Ricciardulli and Garcia 2000; Chun et al. 2007; Chan and Nigam 2009; Grimsdell et al. 2010; Stephan and Alexander 2015). Given that the cloud-top momentum flux is proportional to the square of the column-maximum CHR, a derivation of more realistic and precise $\mathrm{CHR}$ is required and remains a topic for future studies.

NCT diagnostics derived from the CGWD parameterization by Chun and Baik (1998) reasonably well represent the NCT generation related to the breaking of CGWs, at least for the two examined cases, which occurred either above the shallow convection or above the dissipating convection. Furthermore, CGWD calculated using 1-yr CFSR global reanalysis data is concentrated in major convection regions; nearly all seasons in the tropical regions, subtropics and midlatitudes in summertime, and midlatitude storm tracks in wintertime. The regional aviation weather forecasting model (e.g., GTG in the United States and KTG in East Asia) revealed relatively poor forecasting skill during summertime based on the existing CAT diagnostics, which mostly represent strong wind shear near the jet stream to be strong during wintertime and springtime (e.g., Kim et al. 2011; Lee and Chun 2014). The NCT diagnostics related to CGWD can improve the forecasting skill of aviation turbulence during midlatitude summertime, where convective activities are dominant but the jet stream is weak.

The turbulence diagnostics calculated using mesoscale model output represent the potential for turbulence rather than explicit calculation of turbulence itself. Therefore, in practice the performance of EDR as a turbulence predictor is not necessarily better than that of other diagnostics. This has been discussed in many previous studies of CAT (e.g., Sharman et al. 2006; Kim and Chun 2012a; Gill and Buchanan 2014; Sharman and Pearson 2017), where many diagnostics (cf. Table 1 of Sharman and Pearson 2017) are considered for turbulence forecasting, instead of a single quantity such as EDR. In future studies, we will examine the performance of each of the eight NCT diagnostics by comparing them to observed in situ flight turbulence observations for more than one year. In this regard, evaluation of the NCT diagnostics proposed in the current study against in situ flight turbulence observations covering wider areas, including the tropics, is important and necessary step that could stimulate improvements to the current global aviation turbulence forecasting model.

It is noteworthy that the CGWs considered in the CGWD parameterization scheme by Chun and Baik (1998) are based on a steady-state convective source, 
9-10 March 2006
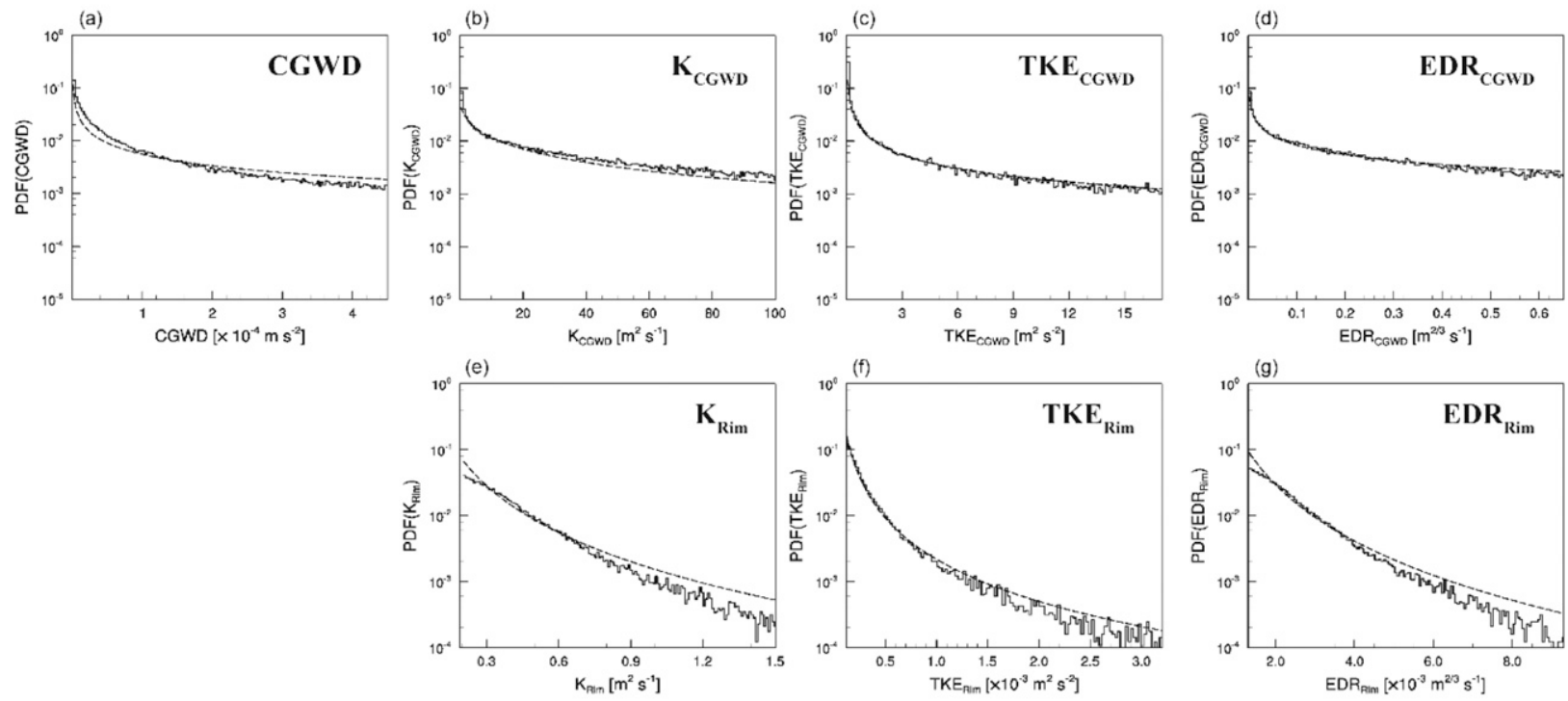

2 September 2007
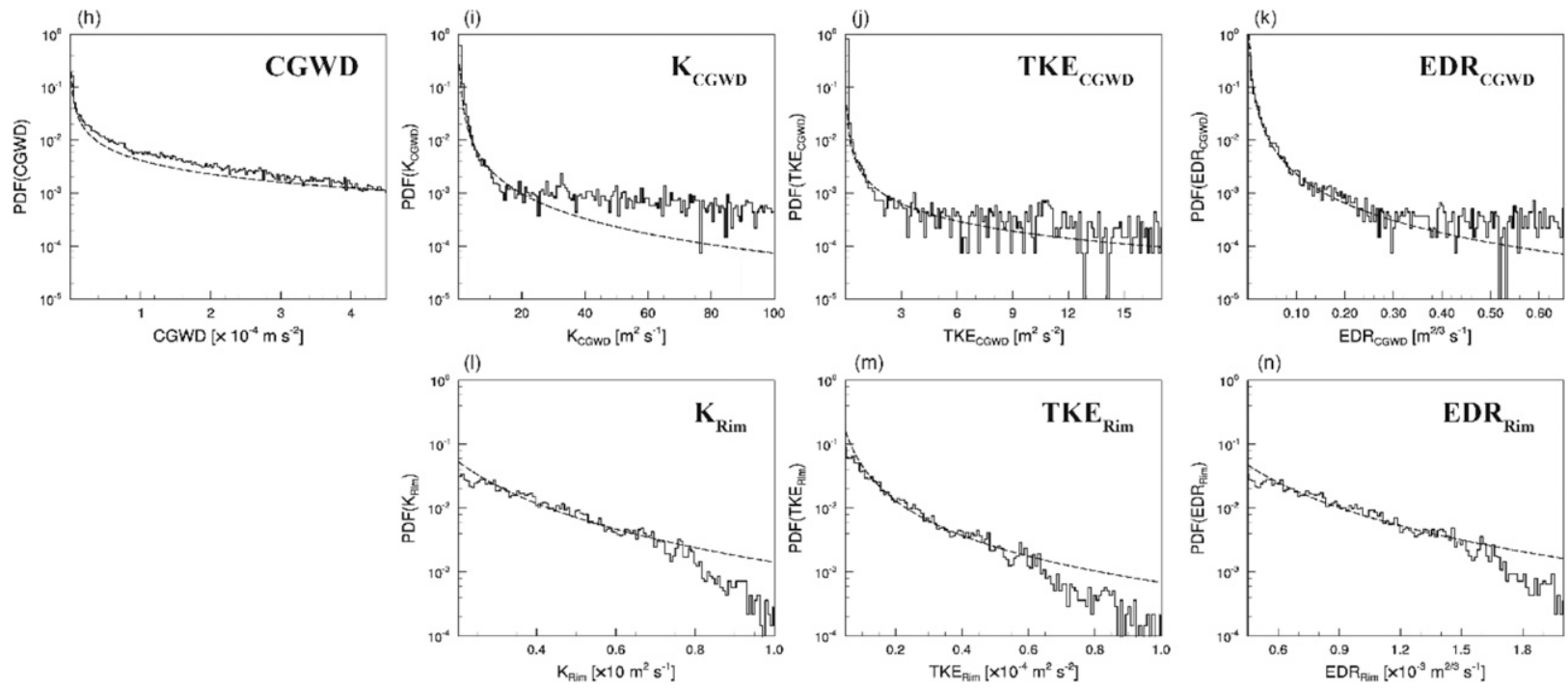

FIG. 17. The PDFs (solid line) and lognormal PDFs (dashed line) of nonzero CGWD-based and $\mathrm{Ri}_{\text {min }}$-based NCT diagnostics calculated between 200 and $250 \mathrm{hPa}$ (a)-(g) from 2300 UTC 9 Mar to 0100 UTC 10 Mar 2006 and (h)-(n) from 0900 to 1100 UTC 2 Sep 2007.

for simplicity. After Chun and Baik (1998), updated CGWD parameterizations considering the transient nature of convective source and GWs have been developed (e.g., Beres et al. 2004; Song and Chun 2005; Choi and Chun 2011; Kang et al. 2017). Although CGWD obtained from these updated parameterizations may have a better theoretical basis, they are not ideal for use in producing NCT diagnostics, because their formulation is much more complicated and they require more time for calculation. Considering the NCT diagnostics proposed in the current study are meant to be easily implemented in an operational aviation turbulence forecasting model, the relatively simple scheme of Chun and Baik (1998) seems well suited for this purpose. However, if an operational global weather forecasting model includes more sophisticated CGWD parameterization schemes mentioned above, for example the Korean Integrated Model (KIM; Choi et al. 2018), the CGWD output can be used directly as a NCT diagnostic without further complicated calculations. The comparison of the current CGWD result with that from any updated CGWD parameterization scheme is a future research topic that needs to be investigated. 
(a) PDF of CGWD

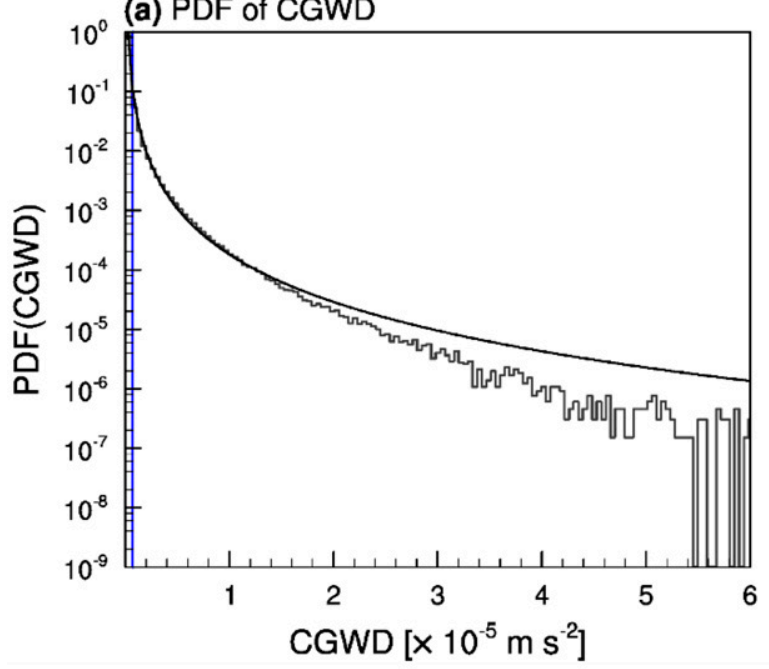

(c) Probability of MOG-level CGWD

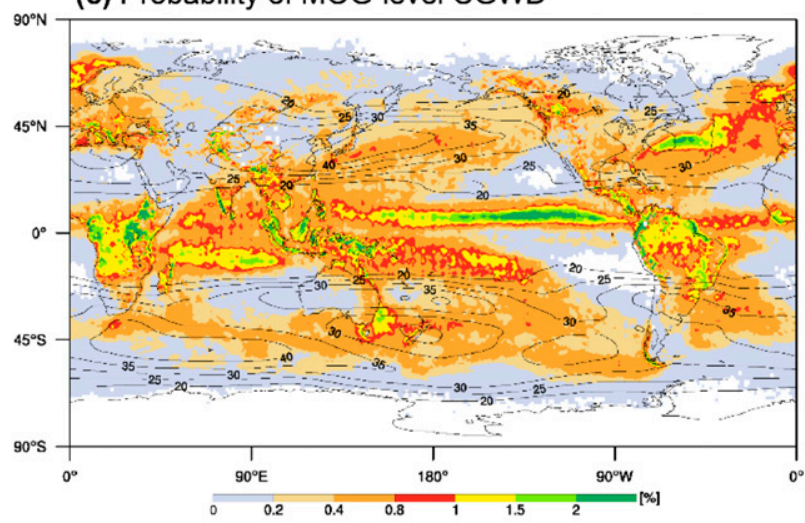

(b) PDF of Ellrod1 index

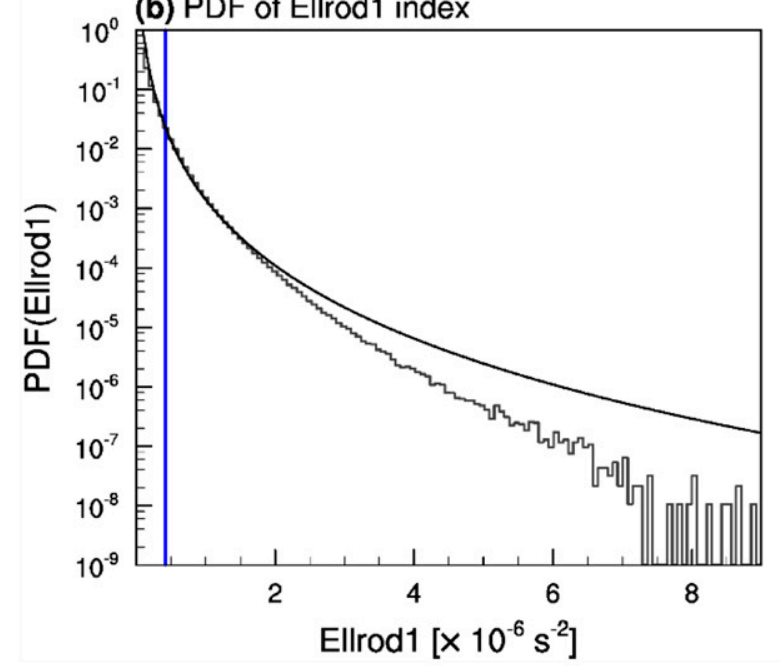

(d) Probability of MOG-level Ellrod1 index

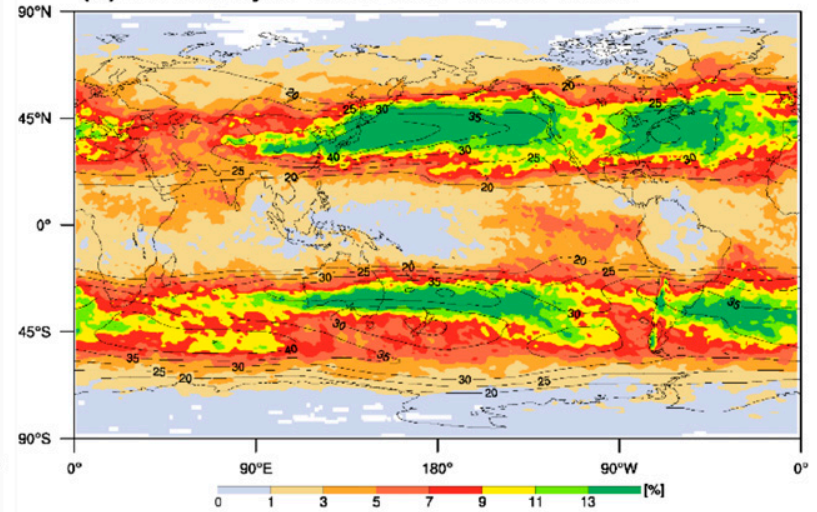

FIG. 18. (a),(b) The PDFs (histogram) and lognormal PDFs (continuous black line) of CGWD and Ellrod1 between 200 and $250 \mathrm{hPa}$ calculated from December 2009 to November 2010 and (c),(d) the horizontal distributions of the probabilities of the MOG-intensity CGWD and Ellrod1 indices averaged from December 2009 through November 2010 between 200 and $250 \mathrm{hPa}$. The 95th percentile of CGWD and Ellrod1 is indicated by the blue line in (a) and (b). The superimposed mean wind (contour) between 200 and $250 \mathrm{hPa}$ is shown in (c) and (d).

Acknowledgments. The authors are grateful to David Ahijevych (NCAR) for constructing Fig. 2. This work was funded by the Korea Meteorological Administration Research and Development Program under Grant KMI 2018-07810.

\section{REFERENCES}

Andrews, D. C., J. R. Holton, and C. B. Leovy, 1987: Linear wave theory. Middle Atmosphere Dynamics, Academic Press, 150-219.

Baek, S., 2017: A revised radiation package of G-packed McICA and two-stream approximation: Performance evaluation in a global weather forecasting model. J. Adv. Model. Earth Syst., 9, 1628-1640, https://doi.org/10.1002/2017MS000994.

Baik, J.-J., and H.-Y. Chun, 1996: Effects of nonlinearity on the atmospheric flow response to low-level heating in a uniform flow. J. Atmos. Sci., 53, 1856-1869, https://doi.org/10.1175/ 1520-0469(1996)053<1856:EONOTA>2.0.CO;2.
Barber, K., G. L. Mullendore, and M. J. Alexander, 2018: Out-ofcloud convective turbulence: Estimation method and impacts of model resolution. J. Appl. Meteor. Climatol., 57, 121-136, https://doi.org/10.1175/JAMC-D-17-0174.1.

Bedard, A. J., F. Canavero, and F. Einaudi, 1986: Atmospheric gravity waves and aircraft turbulence encounters. J. Atmos. Sci., 43, 2838-2844, https://doi.org/10.1175/1520-0469(1986) $043<2838$ :AGWAAT $>2.0$. CO;2.

Benjamin, S. G., and Coauthors, 2004: An hourly assimilationforecast cycle: The RUC. Mon. Wea. Rev., 132, 495-518, https://doi.org/10.1175/1520-0493(2004)132<0495:AHACTR $>$ 2.0.CO;2.

_- and Coauthors, 2016: A North American hourly assimilation and model forecast cycle: The Rapid Refresh. Mon. Wea. Rev., 144, 1669-1694, https://doi.org/10.1175/MWR-D-15-0242.1.

Beres, J. H., M. J. Alexander, and J. R. Holton, 2004: A method of specifying the gravity wave spectrum and above convection based on latent heating properties and background wind. J. Atmos. Sci., 61, 324-337, https://doi.org/10.1175/1520-0469(2004) $061<0324$ :AMOSTG $>2.0 . \mathrm{CO} ;$. 
Caine, S., T. P. Lane, P. T. May, C. Jakob, M. J. Manton, S. T. Siems, and J. Pinto, 2013: Statistical assessment of tropical convectionpermitting model simulations using a cell-tracking algorithm. Mon. Wea. Rev., 141, 557-581, https://doi.org/10.1175/MWR-D11-00274.1.

Chan, S. C., and S. Nigam, 2009: Residual diagnosis of diabatic heating from ERA-40 and NCEP reanalyses: Intercomparisons with TRMM. J. Climate, 22, 414-428, https://doi.org/ 10.1175/2008JCLI2417.1.

Chen, F., and J. Dudhia, 2001: Coupling an advanced land surfacehydrology model with the Penn State-NCAR MM5 modeling system. Part I: Model implementation and sensitivity. Mon. Wea. Rev., 129, 569-585, https://doi.org/10.1175/1520-0493(2001) $129<0569$ :CAALSH $>2.0 . \mathrm{CO} ; 2$.

Choi, H.-J., and H.-Y. Chun, 2011: Momentum flux spectrum of convective gravity waves. Part I: An update of a parameterization using mesoscale simulations. J. Atmos. Sci., 68, 739-759, https://doi.org/10.1175/2010JAS3552.1.

—, J.-Y. Han, M.-S. Koo, H.-Y. Chun, Y.-H. Kim, and S.-Y. Hong, 2018: Effects of non-orographic gravity wave drag on seasonal and medium-range predictions in a global forecast model. Asia-Pac. J. Atmos. Sci., 54, 385-402, https://doi.org/ 10.1007/s13143-018-0023-1.

Chou, M.-D., and M. J. Suarez, 1994: An efficient thermal infrared radiation parameterization for use in general circulation models. NASA Tech. Memo. 104606, No. 3, 85 pp.

Chun, H.-Y., and J.-J. Baik, 1998: Momentum flux by thermally induced internal gravity waves and its approximation for largescale models. J. Atmos. Sci., 55, 3299-3310, https://doi.org/ 10.1175/1520-0469(1998)055<3299:MFBTII > 2.0.CO;2.

—_, M.-D. Song, J.-W. Kim, and J.-J. Baik, 2001: Effects of gravity wave drag induced by cumulus convection on the atmospheric general circulation. J. Atmos. Sci., 58, 302-319, https://doi.org/10.1175/1520-0469(2001)058<0302:EOGWDI> 2.0.CO;2.

_ - I.-S. Song, J.-J. Baik, and Y.-J. Kim, 2004: Impact of a convectively forced gravity wave drag parameterization in NCAR CCM3. J. Climate, 17, 3530-3547, https://doi.org/10.1175/15200442(2004)017<3530:IOACFG>2.0.CO;2.

—, J.-S. Goh, I.-S. Song, and L. Ricciardulli, 2007: Latitudinal variations of the convective source and condition of inertiogravity waves in the tropics. J. Atmos. Sci., 64, 1603-1618, https://doi.org/10.1175/JAS3891.1.

Deardorff, J. W., 1980: Stratocumulus-capped mixed layers derived from a three-dimensional model. Bound.-Layer Meteor., 18, 495-527, https://doi.org/10.1007/BF00119502.

Dudhia, J., 1989: Numerical study of convection observed during the Winter Monsoon Experiment using a mesoscale two-dimensional model. J. Atmos. Sci., 46, 3077-3107, https://doi.org/10.1175/15200469(1989)046<3077:NSOCOD > 2.0.CO;2.

— 1996: A multilayer soil temperature model for MM5. Preprints, Sixth PSU/NCAR Mesoscale Model Users' Workshop, Boulder, CO, NCAR, 49-50.

Ellrod, G. P., and D. I. Knapp, 1992: An objective clear-air turbulence forecasting technique: Verification and operational use. Wea. Forecasting, 7, 150-165, https://doi.org/10.1175/ 1520-0434(1992)007<0150:AOCATF > 2.0.CO;2.

Federal Aviation Administration, 2012: Aeronautical information manual. FAA Doc., 762 pp.

2017: Safety of flight. Aeronautical information manual. FAA Doc., 435-539.

Fedorovich, E., R. Rotunno, and B. Stevens, Eds., 2004: Atmospheric Turbulence and Mesoscale Meteorology: Scientific
Research Inspired by Doug Lilly. Cambridge University Press, $280 \mathrm{pp}$.

Gill, P. G., and P. Buchanan, 2014: An ensemble based turbulence forecasting system. Meteor. Appl., 21, 12-19, https://doi.org/ 10.1002/met.1373.

Gilman, D. L., F. J. Fuglister, and J. M. Mitchell Jr., 1963: On the power spectrum of "red noise." J. Atmos. Sci., 20, 182-184, https://doi.org/10.1175/1520-0469(1963)020<0182:OTPSON $>$ 2.0.CO;2.

Golding, W. L., 2000: Turbulence and its impact of commercial aviation. J. Aviat./Aerosp. Educ. Res., 11, 8, https://doi.org/ 10.15394/jaaer.2002.1301.

Grimsdell, A. W., M. J. Alexander, P. T. May, and L. Hoffmann, 2010: Model study of waves generated by convection with direct validation via satellite. J. Atmos. Sci., 67, 1617-1631, https://doi.org/10.1175/2009JAS3197.1.

Hamilton, D. W., and F. H. Proctor, 2002: Convectively induced turbulence encountered during NASA's fall-2000 flight experiments. Extended Abstracts, 10th Conf. on Aviation, Range, and Aerospace Meteorology, Portland, OR, Amer. Meteor. Soc., 10.8, https://ams.confex.com/ams/pdfpapers/40038.pdf.

Hong, S.-Y., and J.-O. J. Lim, 2006: The WRF single-moment 6-class microphysics scheme (WSM6). J. Korean Meteor. Soc., 42, $129-151$.

Janjić, Z. I., 2001: Nonsingular implementation of the MellorYamada level 2.5 scheme in the NCEP Meso model. NCEP Office Note 437, 61 pp., http://www.emc.ncep.noaa.gov/officenotes/ newernotes/on437.pdf.

Kain, J. S., 2004: The Kain-Fritsch convective parameterization: An update. J. Appl. Meteor., 43, 170-181, https://doi.org/ 10.1175/1520-0450(2004)043<0170:TKCPAU>2.0.CO;2.

Kang, M.-J., H.-Y. Chun, and Y.-H. Kim, 2017: Momentum flux of convective gravity wave derived from an offline gravity wave parameterization. Part I: Spatiotemporal variations at source level. J. Atmos. Sci., 74, 3167-3189, https://doi.org/10.1175/ JAS-D-17-0053.1.

Kaplan, M. L., A. W. Huffman, K. M. Lux, J. J. Charney, A. R. Riordan, and Y.-L. Lin, 2005: Characterizing the severe turbulence environments associated with commercial aviation accidents. Part 1: A 44-case study synoptic observational analyses. Meteor. Atmos. Phys., 88, 129-152, https://doi.org/ 10.1007/s00703-004-0080-0.

Kim, J.-H., and H.-Y. Chun, 2011: Statistics and possible sources of aviation turbulence over South Korea. J. Appl. Meteor. Climatol., 50, 311-324, https://doi.org/10.1175/2010JAMC2492.1.

— turbulence above deep convection. J. Appl. Meteor. Climatol., 51, 1180-1200, https://doi.org/10.1175/JAMC-D-11-0140.1.

_ and _ 2012b: Development of the Korean aviation Turbulence Guidance (KTG) system using the operational Unified Model (UM) of the Korea Meteorological Administration (KMA) and pilot reports (PIREPs) (in Korean with English abstract). J. Korean Soc. Aviat. Aeronaut., 20, 76-83, https:// doi.org/10.12985/ksaa.2012.20.4.076.

, R. D. Sharman, and T. L. Keller, 2011: Evaluations of upper-level turbulence diagnostics performance using the Graphical Turbulence Guidance (GTG) system and pilot reports (PIREPs) over East Asia. J. Appl. Meteor. Climatol., 50, 1936-1951, https://doi.org/10.1175/JAMC-D-10-05017.1.

,,,-- and S. B. Trier, 2014: The role of vertical shear on aviation turbulence within cirrus bands of a simulated western Pacific cyclone. Mon. Wea. Rev., 142, 2794-2813, https:// doi.org/10.1175/MWR-D-14-00008.1. 
Kim, S.-H., and H.-Y. Chun, 2016: Aviation turbulence encounters detected from aircraft observations: Spatiotemporal characteristics and application to Korean aviation turbulence guidance. Meteor. Appl., 23, 594-604, https://doi.org/10.1002/ met.1581.

Kim, S.-Y., and H.-Y. Chun, 2010: Stratospheric gravity waves generated by Typhoon Saomai (2006): Numerical modeling in a moving frame following the typhoon. J. Atmos. Sci., 67 , 3617-3636, https://doi.org/10.1175/2010JAS3374.1.

Knapp, K. R., and Coauthors, 2011: Globally gridded satellite observations for climate studies. Bull. Amer. Meteor. Soc., 92, 893-907, https://doi.org/10.1175/2011BAMS3039.1.

Knox, J. A., D. W. McCann, and P. D. Williams, 2008: Application of the Lighthill-Ford theory of spontaneous imbalance to clear-air turbulence forecasting. J. Atmos. Sci., 65, 3292-3304, https://doi.org/10.1175/2008JAS2477.1.

Lane, T. P., and R. D. Sharman, 2008: Some influences of background flow conditions on the generation of turbulence due to gravity wave breaking above deep convection. J. Appl. Meteor. Climatol., 47, 2777-2796, https://doi.org/10.1175/ 2008JAMC1787.1.

,-- _ T. L. Clark, and H.-M. Hsu, 2003: An investigation of turbulence generation mechanisms above deep convection. J. Atmos. Sci., 60, 1297-1321, https://doi.org/10.1175/15200469(2003)60<1297:AIOTGM > 2.0.CO;2.

_ J. D. Doyle, R. D. Sharman, M. A. Shapiro, and C. D. Watson, 2009: Statistics and dynamics of aircraft encounters of turbulence over Greenland. Mon. Wea. Rev., 137, 2687-2702, https://doi.org/10.1175/2009MWR2878.1.

_ , R. D. Sharman, S. B. Trier, R. G. Fovell, and J. K. Williams, 2012: Recent advances in the understanding of near-cloud turbulence. Bull. Amer. Meteor. Soc., 93, 499-515, https:// doi.org/10.1175/BAMS-D-11-00062.1.

Lee, D.-B., and H.-Y. Chun, 2014: Development of the seasonal Korean aviation Turbulence Guidance (KTG) system using the regional unified model of the Korea Meteorological Administration (KMA) (in Korean with English abstract). Atmosphere, 24, 235-243, https://doi.org/10.14191/ Atmos.2014.24.2.235.

_ and - 2015a: A statistical analysis of aviation turbulence observed in pilot report (PIREP) over East Asia including South Korea (in Korean with English abstract). Atmosphere, 25, 129-140, https://doi.org/10.14191/Atmos.2015.25.1.129.

— , and _ 2015b: Development of the Korean Peninsula Korean aviation Turbulence Guidance (KP-KTG) system using the Local Data Assimilation and Prediction System (LDAPS) of the Korea Meteorological Administration (KMA) (in Korean with English abstract). Atmosphere, 25, 367-374, https://doi.org/10.14191/Atmos.2015.25.2.367.

— , and - 2018: A numerical study of aviation turbulence encountered on 13 February 2013 over the Yellow Sea between China and Korea. J. Appl. Meteor. Climatol., 57, 1043 1060, https://doi.org/10.1175/JAMC-D-17-0247.1.

Lester, P. F., 1994: Turbulence: A New Perspective for Pilots. Jeppesen Sanderson, 212 pp.

Lilly, D. K., 1962: On the numerical simulation of buoyant convection. Tellus, 14, 148-172, https://doi.org/10.3402/ tellusa.v14i2.9537.

- 1966: On the application of the eddy viscosity concept in the inertial sub-range of turbulence. NCAR Tech. Rep. 123, 18 pp., https://doi.org/10.5065/D67H1GGQ

Lin, Y.-L., and H.-Y. Chun, 1991: Effects of diabatic cooling in a shear flow with a critical level. J. Atmos. Sci., 48, 2476-2491,
https://doi.org/10.1175/1520-0469(1991)048<2476:EODCIA > 2.0.CO;2.

, R. D. Farley, and H. D. Orville, 1983: Bulk parameterization of a snow field in a cloud model. J. Climate Appl. Meteor., 22, 1065-1092, https://doi.org/10.1175/1520-0450(1983)022<1065: BPOTSF $>2.0 . \mathrm{CO} ; 2$.

Lindzen, R. S., 1981: Turbulence and stress due to gravity wave and tidal breakdown. J. Geophys. Res., 86, 9707-9714, https:// doi.org/10.1029/JC086iC10p09707.

Meneguz, E., H. Wells, and D. Turp, 2016: An automated system to quantify aircraft encounters with convectively induced turbulence over Europe and the northeast Atlantic. J. Appl. Meteor. Climatol., 55, 1077-1089, https://doi.org/10.1175/ JAMC-D-15-0194.1.

Mlawer, E. J., S. J. Taubman, P. D. Brown, M. J. Iacono, and S. A. Clough, 1997: Radiative transfer for inhomogeneous atmosphere: RRTM, a validated correlated-k model for the longwave. J. Geophys. Res., 102, 16663-16682, https://doi.org/ 10.1029/97JD00237.

Moeng, C.-H., and J. C. Wyngaard, 1988: Spectral analysis of largeeddy simulations of the convective boundary layer. J. Atmos. Sci., 45, 3573-3587, https://doi.org/10.1175/1520-0469(1988) 045<3573:SAOLES $>2.0$. CO 2

Monette, S. A., and J. M. Sieglaff, 2014: Probability of convectively induced turbulence associated with geostationary satelliteinferred cloud-top cooling. J. Appl. Meteor. Climatol., 53, 429436, https://doi.org/10.1175/JAMC-D-13-0174.1.

Palmer, T. N., G. J. Shutts, and R. Swinbank, 1986: Alleviation of a systematic westerly bias in general circulation and numerical weather prediction models through an orographic gravity wave drag parameterization. Quart. J. Roy. Meteor. Soc., 112, 1001-1039, https://doi.org/10.1002/qj.49711247406.

Pantley, K. C., and P. F. Lester, 1990: Observations of severe turbulence near thunderstorm tops. J. Appl. Meteor., 29, 1171-1179, https://doi.org/10.1175/1520-0450(1990)029<1171: OOSTNT $>2.0 . \mathrm{CO} ; 2$.

Pearson, J., and R. D. Sharman, 2017: Prediction of energy dissipation rates for aviation turbulence. Part II: Nowcasting convective and nonconvective turbulence. J. Appl. Meteor. Climatol., 56, 339-351, https://doi.org/10.1175/JAMC-D-160312.1.

Ricciardulli, L., and R. R. Garcia, 2000: The excitation of equatorial waves by deep convection in the NCAR Community Climate Model (CCM3). J. Atmos. Sci., 57, 3461-3487, https://doi.org/10.1175/1520-0469(2000)057<3461:TEOEWB> 2.0.CO;2.

Riddaway, R. W., 1998: Notes and news. Meteor. Appl., 5, 88-92, https://doi.org/10.1017/S135048279801055X.

Saha, S., and Coauthors, 2010: The NCEP Climate Forecast System Reanalysis. Bull. Amer. Meteor. Soc., 91, 1015-1057, https:// doi.org/10.1175/2010BAMS3001.1.

- and Coauthors, 2014: The NCEP Climate Forecast System version 2. J. Climate, 27, 2185-2208, https://doi.org/10.1175/ JCLI-D-12-00823.1

Schwartz, B., 1996: The quantitative use of PIREPs in developing aviation weather guidance products. Wea. Forecasting, 11, 372-384, https://doi.org/10.1175/1520-0434(1996)011<0372: TQUOPI $>2.0 . \mathrm{CO} ; 2$.

Sharman, R. D., and T. P. Lane, Eds., 2016: Aviation Turbulence: Processes, Detection, Prediction. Springer, 523 pp., https:// doi.org/10.1007/978-3-319-23630-8.

, and J. Pearson, 2017: Prediction of energy dissipation rates for aviation turbulence. Part I: Forecasting nonconvective 
turbulence. J. Appl. Meteor. Climatol., 56, 317-337, https:// doi.org/10.1175/JAMC-D-16-0205.1.

, and S. B. Trier, 2019: Influences of gravity waves on convectively induced turbulence (CIT): A review. Pure Appl. Geophys., 176, 1923-1958, https://doi.org/10.1007/s00024-0181849-2.

— C. Tebaldi, G. Wiener, and J. Wolff, 2006: An integrated approach to mid- and upper-level turbulence forecasting. Wea. Forecasting, 21, 268-287, https://doi.org/10.1175/WAF924.1.

- S. B. Trier, T. P. Lane, and J. D. Doyle, 2012: Sources and dynamics of turbulence in the upper troposphere and lower stratosphere: A review. Geophys. Res. Lett., 39, L12803, https://doi.org/10.1029/2012GL051996.

_ L. B. Cornman, G. Meymaris, J. Pearson, and T. Farrar, 2014: Description and derived climatologies of automated in situ eddy-dissipation-rate reports of atmospheric turbulence. J. Appl. Meteor. Climatol., 53, 1416-1432, https://doi.org/ 10.1175/JAMC-D-13-0329.1.

Skamarock, W. C., 2004: Evaluating mesoscale NWP models using kinetic energy spectra. Mon. Wea. Rev., 132, 3019-3032, https://doi.org/10.1175/MWR2830.1.

— spheric model for weather research and forecasting applications. J. Comput. Phys., 227, 3465-3485, https://doi.org/10.1016/ j.jcp.2007.01.037.

_ , S.-H. Park, J. B. Klemp, and C. Snyder, 2014: Atmospheric kinetic energy spectra from global high-resolution nonhydrostatic simulations. J. Atmos. Sci., 71, 4369-4381, https://doi.org/10.1175/ JAS-D-14-0114.1.

Smagorinsky, J., 1963: General circulation experiments with the primitive equations: I. The basic experiment. Mon. Wea. Rev., 91, 99-164, https://doi.org/10.1175/1520-0493(1963)091<0099: GCEWTP $>2.3 . \mathrm{CO} ; 2$.

Smith, R. B., and Y.-L. Lin, 1982: The addition of heat to a stratified airstream with application to the dynamics of orographic rain. Quart. J. Roy. Meteor. Soc., 108, 353-378, https://doi.org/ 10.1002/qj.49710845605.

Song, I.-S., and H.-Y. Chun, 2005: Momentum flux spectrum of convectively forced internal gravity waves and its application to gravity wave drag parameterization. Part I: Theory. J. Atmos. Sci., 62, 107-124, https://doi.org/10.1175/JAS-3363.1.

Stephan, C., and M. J. Alexander, 2015: Realistic simulations of atmospheric gravity waves over the continental U.S. using precipitation radar data. J. Adv. Model. Earth Syst., 7, 823835, https://doi.org/10.1002/2014MS000396.
Storer, L. N., P. D. Williams, and M. M. Joshi, 2017: Global response of clear-air turbulence to climate change. Geophys. Phys. Lett., 44, 9976-9984, https://doi.org/10.1002/2017GL074618.

Trier, S. B., and R. D. Sharman, 2009: Convection-permitting simulations of the environment supporting widespread turbulence within the upper-level outflow of a mesoscale convection system. Mon. Wea. Rev., 137, 1972-1990, https://doi.org/ 10.1175/2008MWR2770.1.

_ , and - 2016: Mechanisms influencing cirrus banding and aviation turbulence near a convectively enhanced upper-level jet stream. Mon. Wea. Rev., 144, 3003-3027, https://doi.org/ 10.1175/MWR-D-16-0094.1.

,-- , R. G. Fovell, and R. G. Frehlich, 2010: Numerical simulation of radial cloud bands within the upper-level outflow of an observed mesoscale convective system. J. Atmos. Sci., 67, 2990-2999, https://doi.org/10.1175/2010JAS3531.1.

,-- , and T. P. Lane, 2012: Influences of moist convection on a cold-season outbreak of clear-air turbulence (CAT). Mon. Wea. Rev., 140, 2477-2496, https://doi.org/10.1175/ MWR-D-11-00353.1.

Tvaryanas, A. P., 2003: Epidemiology of turbulence-related injuries in airline cabin crew, 1992-2001. Aviat. Space Environ. Med., 74, 970-976.

Walters, D., and Coauthors, 2017: The Met Office Unified Model Global Atmosphere 6.0/6.1 and JULES Global Land 6.0/6.1 configurations. Geosci. Model Dev., 10, 1487-1520, https:// doi.org/10.5194/gmd-10-1487-2017.

Warner, M., 2013: Boeing: Current market outlook 2013-2032. Boeing Commercial Airlines, 37 pp., http://speednews.com/ documentaccess/103536_cmo2013.pdf.

Wilks, D. S., 1995: Statistical Methods in the Atmospheric Sciences: An Introduction. Academic Press, $467 \mathrm{pp}$.

Williams, J. K., 2014: Using random forests to diagnose aviation turbulence. Mach. Learn., 95, 51-70, https://doi.org/10.1007/ s10994-013-5346-7.

Williams, P. D., 2017: Increased light, moderate, and severe clearair turbulence in response to climate change. Adv. Atmos. Sci., 34, 576-586, https://doi.org/10.1007/s00376-017-6268-2.

Wolff, J. K., and R. D. Sharman, 2008: Climatology of upperlevel turbulence over the contiguous United States. J. Appl. Meteor. Climatol., 47, 2198-2214, https://doi.org/10.1175/ 2008JAMC1799.1.

Zovko-Rajak, D., and T. P. Lane, 2014: The generation of nearcloud turbulence in idealized simulations. J. Atmos. Sci., 71, 2430-2451, https://doi.org/10.1175/JAS-D-13-0346.1. 